\title{
Negative and Positive Affect Regulation in a Transdiagnostic Internet-Based Protocol for Emotional Disorders: Randomized Controlled Trial
}

Amanda Díaz-García ${ }^{1}$, PhD; Alberto González-Robles ${ }^{1}$, PhD; Azucena García-Palacios ${ }^{2,3}$, PhD; Javier Fernández-Álvarez ${ }^{4}$, MSc; Diana Castilla ${ }^{3,5}$, PhD; Juana María Bretón ${ }^{2}, \mathrm{PhD}$; Rosa María Baños ${ }^{3,5}$, PhD; Soledad Quero $^{2}, \mathrm{PhD}$; Cristina Botella ${ }^{2,3}, \mathrm{PhD}$

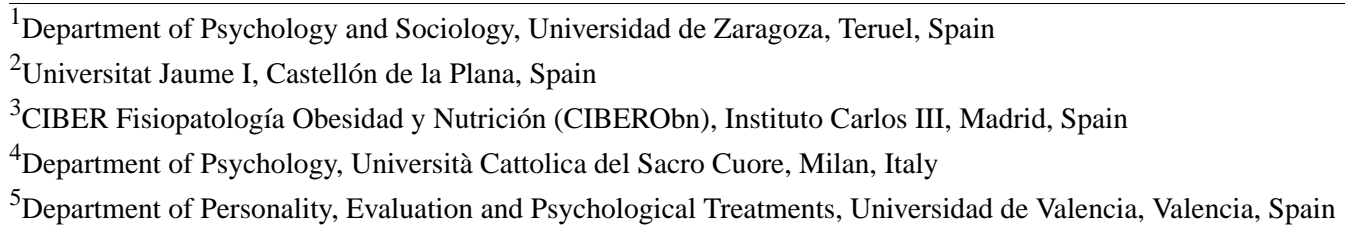

Corresponding Author:

Amanda Díaz-García, PhD

Department of Psychology and Sociology

Universidad de Zaragoza

Calle Cdad. Escolar, S/N, 44003 Teruel

Teruel, 44003

Spain

Phone: 34878618154

Email: amandadiaz@unizar.es

\begin{abstract}
Background: Emotional disorders (EDs) are among the most prevalent mental disorders. Existing evidence-based psychological treatments are not sufficient to reduce the disease burden of mental disorders. It is therefore essential to implement innovative solutions to achieve a successful dissemination of psychological treatment protocols, and in this regard, the use of information and communication technologies such as the internet can be very useful. Furthermore, the literature suggests that not everyone with an ED receives the appropriate treatment. This situation has led to the development of new intervention proposals based on the transdiagnostic perspective, which attempts to address the underlying processes common to EDs. Most of these transdiagnostic interventions focus primarily on downregulating negative affectivity (NA), and less attention has been paid to strengths and the upregulation of positive affectivity, despite its importance for well-being and mental health.

Objective: This study aims to evaluate the efficacy of a transdiagnostic internet-based treatment for EDs in a community sample.

Methods: A 3-armed randomized controlled trial was conducted. A total of 216 participants were randomly assigned to a transdiagnostic internet-based protocol (TIBP), a TIBP+ positive affect (PA) component, or a waiting list (WL) control group. The treatment protocol contained core components mainly addressed to downregulate NA (ie, present-focused emotional awareness and acceptance, cognitive flexibility, behavioral and emotional avoidance patterns, and interoceptive and situational exposure) as well as a PA regulation component to promote psychological strengths and enhance well-being. Data on depression, anxiety, quality of life, neuroticism and extraversion, and PA/NA before and after treatment were analyzed. Expectations and opinions of treatment were also analyzed.

Results: Within-group comparisons indicated significant pre-post reductions in the two experimental conditions. In the TIBP+PA condition, the effect sizes were large for all primary outcomes $(d=1.42$, Beck Depression Inventory [BDI-II]; $d=0.91$, Beck Anxiety Inventory [BAI]; $d=1.27$, Positive and Negative Affect Schedule-Positive [PANAS-P]; $d=1.26$, Positive and Negative Affect Schedule-Negative [PANAS-N]), whereas the TIBP condition yielded large effect sizes for BDI-II $(d=1.19)$ and PANAS-N $(d=1.28)$ and medium effect sizes for BAI $(d=0.63)$ and PANAS-P $(d=0.69)$. Between-group comparisons revealed that participants who received one of the two active treatments scored better at posttreatment than WL participants. Although there were no statistically significant differences between the two intervention groups on the PA measure, effect sizes were consistently larger in the TIBP+PA condition than in the standard transdiagnostic protocol.
\end{abstract}


Conclusions: Overall, the findings indicate that EDs can be effectively treated with a transdiagnostic intervention via the internet, as significant improvements in depression, anxiety, and quality of life measures were observed. Regarding PA measures, promising effects were found, but more research is needed to study the role of PA as a therapeutic component.

Trial Registration: ClinicalTrials.gov NCT02578758; https://clinicaltrials.gov/ct2/show/NCT02578758

International Registered Report Identifier (IRRID)： RR2-10.1186/s12888-017-1297-z

(J Med Internet Res 2021;23(2):e21335) doi: 10.2196/21335

\section{KEYWORDS}

transdiagnostic; positive affectivity; negative affectivity; emotion regulation; emotional disorders; internet

\section{Introduction}

\section{Transdiagnostic Treatments for the Common Psychopathological Processes Underlying Emotional Disorders}

Emotional disorders (EDs) are defined as anxiety and unipolar mood disorders. These disorders have been grouped based on their common biological and psychological vulnerabilities [1]. The estimated lifetime prevalence rates for EDs are high $(28.8 \%$ for anxiety disorders and $20.8 \%$ for mood disorders). In addition, the co-occurrence of multiple EDs has also been found to be elevated, with studies showing that more than $40 \%$ of people with one diagnosis also met the diagnostic criteria for a second disorder over a 12-month period [2].

In recent years, research has demonstrated that evidence-based psychological treatments (EBTs) are effective in the treatment of EDs [3]. However, there has been little success in decreasing the prevalence and incidence of mental illness, and only a small proportion of people in need actually receive adequate psychological treatment [4]. In addition, disseminating EBTs has become a real challenge because of their cost, the duration of the treatments, and the lack of well-qualified professionals [5], which can explain why EBTs are underutilized in clinical practice settings [6].

Recently, transdiagnostic approaches have emerged that address the common characteristics found in cognitive, behavioral, emotional, and other dysregulation areas underlying different EDs, that is, the biological and psychological vulnerabilities shared by different mental disorders [7,8]. With regard to transdiagnostic processes, maladaptive emotion regulation strategies have been suggested as potential explanatory factors underlying the comorbidity across EDs [9].

In response to transdiagnostic approaches, several transdiagnostic treatments have been developed to provide patients with a set of skills geared specifically toward common vulnerabilities [10]. One example of these treatments is the Unified Protocol (UP) [7], which was designed to be applicable across different EDs and represented a significant shift toward transdiagnostic psychological treatments for EDs [11,12]. The UP has been tested and results indicate that it is effective in reducing negative affect (NA) [13], with improvements maintained at the 18-month follow-up [14]. Furthermore, the effect of the UP has been shown on the two temperament dimensions of neuroticism (N)/behavioral inhibition (BI) and extraversion (E)/behavioral activation (BA) [15].
Mounting evidence demonstrates the efficacy of transdiagnostic treatments in patients with EDs compared with control groups [16-19], showing that transdiagnostic treatments are just as effective as disorder-specific cognitive behavioral therapy (CBT) $[12,20]$. The data suggest that a transdiagnostic treatment for EDs might be more widely effective across a diverse range of mental disorders, addressing different disorders with a single protocol [21]. More specifically, a recent meta-analysis showed that the UP is more effective compared with different control groups, such as treatment as usual, waitlist, and medication control groups, in treating anxiety and depressive symptoms [22].

\section{The Role of Positive Affect in EDs}

Regarding the temperamental vulnerabilities, some authors have identified two essential dimensions of temperament in the etiology and course of EDs: N/NA and E/positive affect (PA) [8]. Hence, neuroticism has been identified as a core factor involved in the development of EDs [23]. In addition, N/NA and E/PA have been closely related to Gray's (1987) constructs of BI and BA, respectively [24-26], and these terms are often used interchangeably as the most stable measures of temperament $[8,15,26,27]$. Thus, people with EDs have higher levels of N/NA/BI [8], and they experience negative emotions more intensely and frequently [28] than people who do not have any ED. In contrast, the dimension of positive emotionality, E/PA/BA, has also been observed in many disorders, suggesting that people with an ED show low levels of E/BA [29], which can predict the onset of depression [30] and increase the severity of the problem [31]. Despite the importance of PA in health and well-being, there is limited research on its promotion; therefore, more research is needed in this area. Furthermore, notwithstanding the recent upsurge in transdiagnostic treatments for EDs, most of these protocols have focused on reducing NA. They have addressed core psychopathological deficits in the way patients experience and respond to negative emotions [32]. However, less attention has been paid to positive emotions or promoting PA [33]. In addition to being involved in the symptomatology of EDs, positive emotionality is considered a core element of mental health, showing beneficial, generalized effects on health and functioning [34-37]. Thus, the relationship between emotion regulation (eg, cognitive reappraisal) and well-being has also been demonstrated [38]. On the basis of the literature that highlights the potential importance of positive emotionality as a treatment component [39-43], it is necessary to develop and test treatment components focused on upregulating PA. 


\section{Internet-Based Treatments}

There are many models for delivering interventions in novel ways that can be scaled up to reach large numbers of people in need [4]. In this regard, information and communication technologies (ICTs) play an important role and can facilitate the availability of EBTs [44]. Specifically, the internet is used for the assessment and treatment of clinical conditions, and it has been established as a useful and effective tool for delivering psychological treatments to treat several psychological disorders [45], particularly depression and anxiety disorders [46]. Moreover, some meta-analyses have revealed that these interventions are as efficacious as face-to-face traditional treatments $[47,48]$.

\section{This Study}

The purpose of this study is to test the efficacy of a web-based psychological treatment protocol for individuals from a community sample with one or more diagnoses of EDs: major depressive disorder (MDD), dysthymic disorder (DD), obsessive-compulsive disorder, and four anxiety disorders: panic disorder (PD), agoraphobia (AG), generalized anxiety disorder (GAD), social anxiety disorder (SAD), anxiety disorder not otherwise specified, and (unipolar) mood disorder not otherwise specified [49]. Rather than focusing solely on NA, the treatment protocol includes 2 types of components: one based on classical perspectives for downregulating NA and the other aimed at upregulating PA. The protocol can be applied either in its traditional format (transdiagnostic internet-based protocol, TIBP) or by including both of these components (TIBP+PA).

Some studies have tested the efficacy of transdiagnostic interventions in improving PA measures. However, these studies do not include a specific component to address PA regulation [13], or they are uncontrolled trials [50-52]. Only one study that evaluated the efficacy of a new transdiagnostic treatment focuses on PA, but it is a pilot study rather than a randomized controlled trial (RCT) [53]. To the best of our knowledge, no published RCT has tested the efficacy of a transdiagnostic internet-based treatment for EDs with a specific component to address PA regulation. Therefore, the aim of this study is to investigate the effectiveness of this transdiagnostic protocol for EDs, with and without the specific component to upregulate PA, versus a wait-list control group. A secondary aim is to test the differential effect of the specific treatment component designed to upregulate PA. Finally, we study patients' acceptance of the program developed to apply the treatment protocol over the internet with minimal support by the clinician. We hypothesized that (1) both self-applied protocol modalities (TIBP and TIBP+PA) would be more effective than the wait-list control condition in the treatment of EDs; (2) both interventions would result in significant improvements in depressive and anxious symptomatology at posttreatment; (3) the TIBP+PA would significantly outperform the TIBP group on PA measures; and (4) both protocols are well accepted, with no statistical differences between conditions.

\section{Methods}

\section{Study Design}

This study was a three-armed superiority RCT in which participants were randomly allocated to 1 of 3 conditions: (1) TIBP, (2) TIBP+PA, and (3) waiting list (WL) control condition. For ethical reasons, participants in the control condition were offered the possibility of receiving the treatment protocol after spending time on the WL (16 weeks), thus leaving no control group for the follow-up measurements. Block randomization was performed to ensure that all primary diagnoses were equally represented across conditions. The trial was registered at ClinicalTrial.gov as NCT02578758 on October 16, 2015. The study was approved by the Ethics Committee of Universitat Jaume I (Castellón, Spain; May 5, 2016) and was conducted in compliance with the study protocol, following the Consolidated Standards of Reporting Trials (CONSORT) statement [54], the CONSORT-eHealth guidelines [55], and the Standard Protocol Items: Recommendations for Interventional Trials guidelines [56,57]. Details of the study protocol have been reported elsewhere [58]. Different effect sizes found in the literature based on the transdiagnostic perspective of EDs were considered to estimate the study power in this study. These calculations were performed with the software program $G^{*}$ Power 3.1 [59] and published in the study protocol [58]. This study reports on pre- to posttreatment data.

\section{Study Population, Recruitment, and Eligibility Criteria}

The clinical trial was conducted in a community sample of individuals diagnosed with one or more of the aforementioned disorders. Participants were recruited from adult volunteers interested in participating in the study between June 2015 and July 2018. Potential participants were attended by phone by the clinical team members (who had at least a university master's degree in general health psychology) to explain the study and clarify any doubts. People interested in participating signed the web-based informed consent form and were assessed taking into account all the inclusion criteria. The inclusion criteria were as follows: (1) being at least 18 years old; (2) meeting the Diagnostic and Statistical Manual of Mental Disorders, Fourth Edition (DSM-IV) diagnostic criteria for EDs; (3) having the ability to understand and read Spanish; (4) having access to the internet and an email address; and (5) providing web-based informed consent. The exclusion criteria were as follows: (1) having schizophrenia, bipolar disorder, or alcohol and/or substance dependence disorder; (2) presence of a high risk of suicide (defined by the Mini-International Neuropsychiatry Interview [60] as greater than or equal to 10 points); (3) presence of medical disease/condition that prevents the participant from carrying out the psychological treatment; and (4) receiving another psychological treatment during the study. Receiving pharmacological treatment was not an exclusion criterion, but any increase and/or change in the medication (in the case of receiving) during the study period implied the participant's exclusion from subsequent analyses. Participants who fulfilled all the study criteria were randomized to one of the three experimental conditions by an independent researcher. This researcher was unaware of the characteristics of the study and had no clinical involvement in the trial or access to the study 
data. Participants agreed to participate before determining which treatment they were allocated. All participants were free to withdraw from the treatment at any time. Access and participation in the study did not involve payment in any case.

\section{The Transdiagnostic Interventions}

The treatment protocol is based on the transdiagnostic perspective derived from the UP [5,7] and some strategies from Marsha Linehan's protocol [61]. Initially, a manualized protocol was developed and structured in a patient and therapist handbook. Later, the protocol was adapted to a multimedia web platform (videos, vignettes, audios, images, etc) to be completely self-applied via the internet [62] through a PC or a tablet. The ease of use of the program has been strengthened because it presents a linear navigation to optimize the treatment structure and make the treatment easier and more attractive to the participants.

The program consists of an assessment protocol and a treatment protocol that includes core components, mainly designed to downregulate NA (present-focused emotional awareness and acceptance, cognitive flexibility, behavioral and emotional avoidance patterns, and interoceptive and situational exposure) and upregulate PA to promote psychological strengths and enhance well-being [63]. The protocol content is adapted from the UP [7] and some of the strategies for emotion regulation from dialectical behavior therapy [61]. The PA regulation component is based mainly on BA strategies [64], strategies to promote pleasant and significant activities linked to values and life goals, and strategies to enhance personal strengths, positive feelings, positive cognitions, and positive behavior $[63,65]$. Furthermore, well-being therapy strategies $[66,67]$ and some concepts from Fredickson's Broaden-and-Build Theory [68] are also included in the program. The PA regulation component takes place after the NA regulation component. The protocol also includes traditional therapeutic components of evidence-based treatment for ED (psychoeducation, motivation for change, and relapse prevention). All the treatment components were developed through two self-applied protocol modalities (TIBP and TIBP+PA) with 12 and 16 modules, respectively, with the only difference being the inclusion or absence of the modules that contain the PA-regulation component. A detailed description of modules that contain the PA regulation component is presented in Multimedia Appendix 1 [64,66,68-77]. The modules in each intervention protocol are described briefly elsewhere [58].

The duration of the program could vary among users, and participants in both treatment conditions had equal access to the protocol for a maximum period of 18 weeks. The program sent weekly messages to the patient to remind him/her to continue to work to benefit from the program. A professional platform was used to send these messages [78]. The program also sent automatic emails with reminders to access the modules when participants had not entered the past 15 days. In addition to this ICT support, human support was also provided through weekly phone calls (maximum of $5 \mathrm{~min}$ ) during the treatment period to resolve any difficulties or doubts, or to remind them of the importance of reviewing the treatment contents.

\section{Outcome Measures}

The assessment protocol was included at the beginning and end of the web-based program. A detailed description of the measures and their aims has been published elsewhere [58]. The measures included in this study are described in Table 1. 
Table 1. Study measures.

\begin{tabular}{|c|c|c|c|c|}
\hline Measure & Aim & Cronbach $\alpha$ & $\omega^{\mathrm{a}}$ & Time of assessment \\
\hline \multicolumn{5}{|l|}{ Diagnostic interview } \\
\hline $\mathrm{MINI}^{\mathrm{b}}$ & Psychiatric diagnosis & $\mathrm{N} / \mathrm{A}^{\mathrm{c}}$ & N/A & $\mathrm{BL}^{\mathrm{d}}$ \\
\hline \multicolumn{5}{|l|}{ Primary outcomes } \\
\hline $\mathrm{BDI}-\mathrm{II}^{\mathrm{e}}$ & Severity of depression & .91 & 0.91 & BL, Post- $\mathrm{T}^{\mathrm{f}}$ \\
\hline $\mathrm{BAI}^{\mathrm{g}}$ & Severity of anxiety & .92 & 0.92 & BL, Post-T \\
\hline PANAS $^{\text {h }}$ & Positive and negative affect & $\mathrm{PA}^{\mathrm{i}}=.91 ; \mathrm{NA}^{\mathrm{j}}=.89$ & $\mathrm{PA}=0.91 ; \mathrm{NA}=0.89$ & BL, Post-T \\
\hline \multicolumn{5}{|l|}{ Secondary outcomes } \\
\hline \multicolumn{5}{|l|}{ Personality measures } \\
\hline NEO FFI ${ }^{k}$ & Neuroticism and extraversion & $\mathrm{N}^{\mathrm{l}}=.81 ; \mathrm{E}^{\mathrm{m}}=.84$ & $\mathrm{~N}=0.82 ; \mathrm{E}=0.84$ & BL, Post-T \\
\hline \multicolumn{5}{|l|}{ Quality of life } \\
\hline EQ-5D ${ }^{\mathrm{n}}$ & Health-related quality of life & .67 & 0.70 & BL, Post-T \\
\hline \multicolumn{5}{|l|}{ Expectation and opinion } \\
\hline Expectation of treatment scale & Expectation of treatment & N/A & N/A & $\mathrm{BL}$ \\
\hline Opinion of treatment scale & Opinion of treatment & N/A & N/A & Post-T \\
\hline
\end{tabular}

${ }^{\mathrm{a}} \omega$ : coefficient omega in this study.

${ }^{\mathrm{b}}$ MINI: Mini-International Neuropsychiatric Interview, Version 5.0.0.

${ }^{\mathrm{c}} \mathrm{N} / \mathrm{A}$ : not applicable.

${ }^{\mathrm{d}} \mathrm{BL}$ : baseline.

${ }^{\mathrm{e}}$ BDI-II: Beck Depression Inventory-II.

${ }^{\mathrm{f}}$ Post-T: posttreatment.

gAI: Beck Anxiety Inventory.

${ }^{h}$ PANAS: Positive and Negative Affect Schedule.

${ }^{\mathrm{i}} \mathrm{PA}$ : positive affect.

${ }^{\mathrm{j}} \mathrm{NA}$ : negative affect.

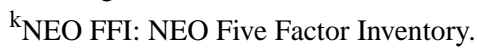

${ }^{\mathrm{l}} \mathrm{N}$ : neuroticism.

${ }^{\mathrm{m}} \mathrm{E}$ : extraversion.

${ }^{\mathrm{n}}$ EQ-5D: EuroQoL-5D Questionnaire.

\section{Statistical Analysis}

Group differences in participants' sociodemographic and clinical data at baseline were examined to confirm that they were comparable after randomization. One-way analysis of variance for continuous variables and Fisher exact tests of independence for categorical variables were used. Intention-to-treat (ITT) using mixed models, with full information maximum likelihood estimation and without any ad hoc imputations were conducted to handle missing data due to participant dropout [79]. This approach uses all available data, does not substitute missing values with assumed or estimated values, and does not assume that the last measurement is stable (the last observation carried forward assumption) [80]. Mixed model analyses are appropriate for RCTs with multiple time points and pre-to postonly designs with substantial dropout rates [81]. The pattern of missingness was investigated to determine its likelihood of being random rather than systematic (missing not at random, MNAR). Subsequently, associations between sample characteristics missingness in the outcome variables were examined ( $t$ tests for continuous variables and Fisher exact tests for categorical variables). A linear mixed model for each outcome measure was implemented using the linear mixed-effects models (MIXED) procedure with one random intercept per subject. An identity covariance structure was specified to model the covariance structure of the random intercept. Significant effects were followed up with pairwise comparisons using the Bonferroni correction. Effect sizes were calculated for withinand between-group comparisons using the standardized observed mean difference proposed by Cohen [82]. To determine the existence of a reliable change in a patient, the reliable change index (RCI; Jacobson and Truax's method) [83] was used. The RCI values for the primary outcomes (Beck Depression Inventory, BDI-II; Beck Anxiety Inventory, BAI; Positive and Negative Affect Schedule-Positive [PANAS-P]; and Positive and Negative Affect Schedule-Negative [PANAS-N]) were calculated for the completer sample (participants who provided data at posttreatment). Fisher exact tests were performed to evaluate group differences in RCI rates for completers. All statistical analyses were conducted using IBM SPSS Statistics 
for Windows, version 22, and SAS software, version 9.4, of the SAS System for Windows.

\section{Results}

\section{Participant Flow and Attrition}

Out of the 573 people who expressed initial interest in the study, as the flow diagram shows (Figure 1), only 402 performed the initial interview. At this stage, 186 participants failed to meet the inclusion criteria. Finally, 216 patients were included in the study, and they were randomly allocated to each experimental condition: TIBP, $n=71 ;$ TIBP+PA, $n=73 ; \mathrm{WL}, \mathrm{n}=72$. Regarding pretreatment assessments, 71 participants performed it in the TIBP, 73 in the TIBP+PA, and 72 in the WL. A similar number of participants performed the posttreatment assessment from both intervention conditions (TIBP, $n=45$; TIBP+PA, $n=46$ ) No significant differences between the three conditions were found in dropout rates $\left(\mathrm{X}_{2}^{2}=3.8, P=.14\right)$. In the TIBP condition, of those who started the program $(n=71), 26$ participants $(26 / 71$, $37 \%$ ) withdrew from the treatment. In the TIBP+PA condition, a similar pattern was found; of those who started the program $(n=73), 27$ participants $(27 / 73,37 \%)$ withdrew from the treatment. Finally, in the WL control group, data from 55 participants were obtained after they had spent 16 weeks on the WL (55/72, 76\% retention; 17/72, 24\% dropout). Overall, of the 216 participants who started the study, 86 participants withdrew from the program. As a result, two patterns of missingness emerged. One of them represented $32 \%$ of the sample $(70 / 216,32.4 \%)$ and the other represented a very low percentage $(16 / 216,7.4 \%)$. Missingness was not related to the characteristics listed in Table 2 in any of the three arms of the RCT (all $P>.05$ in both patterns). Therefore, patterns of missingness were not found to be MNAR and the decision to continue the analysis with the available data was made $[84,85]$.

Figure 1. Flowchart of participants. DSM-IV-TR: Diagnostic and Statistical Manual of Mental Disorders, Fourth Edition, Text Revision; ED: emotional disorder; TIBP: Transdiagnostic internet-Based Protocol; PA: positive affect; WL: Waiting List; ITT: intention-to-treat.

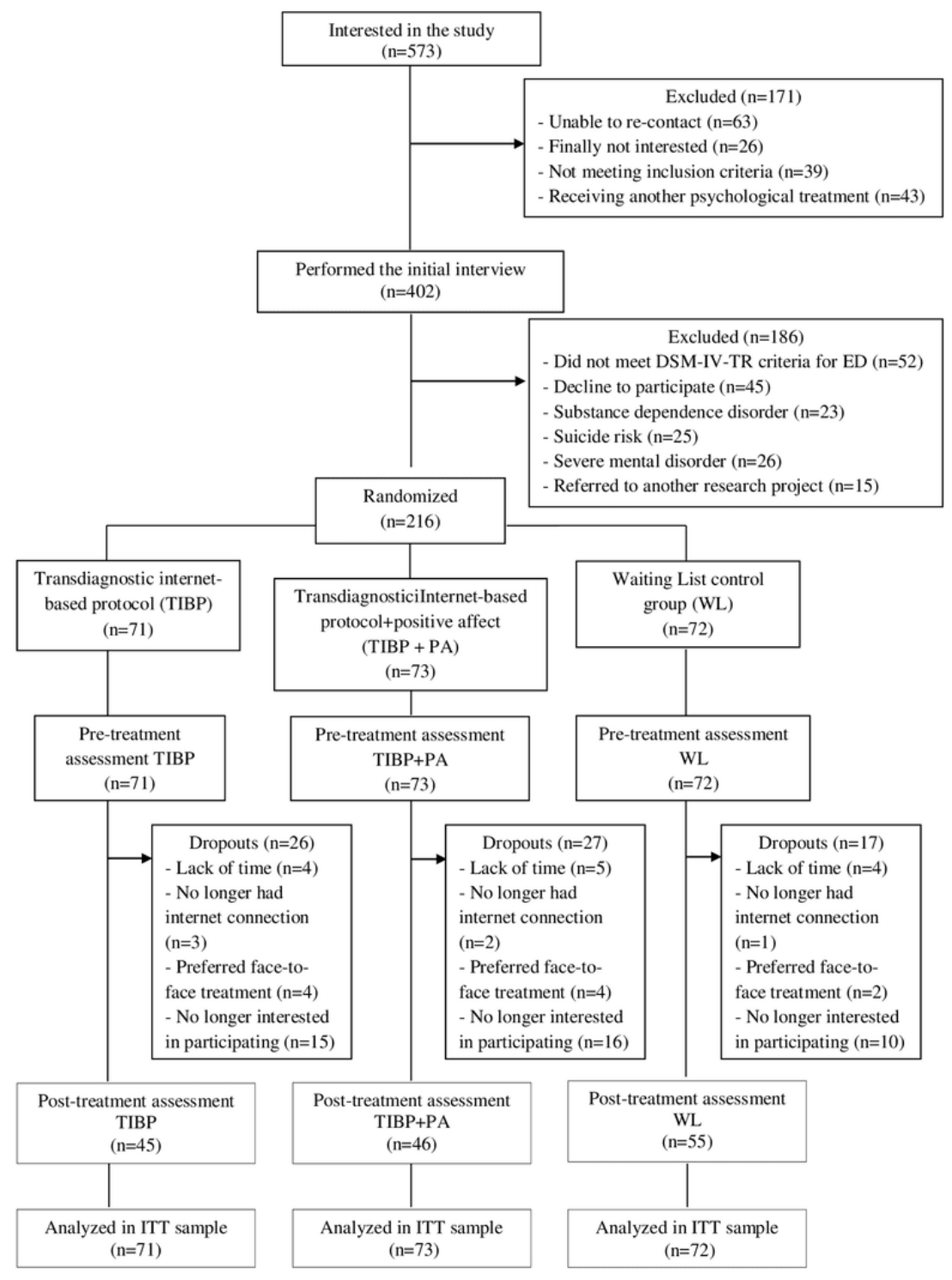


Table 2. Demographic characteristics of participants at pre-assessment $(\mathrm{N}=216)$.

\begin{tabular}{lllll}
\hline Variable & $\operatorname{TIBP}^{\mathrm{a}}(\mathrm{n}=71)$ & $\mathrm{TIBP}_{\mathrm{PA}}^{\mathrm{b}}(\mathrm{n}=73)$ & $\mathrm{WL}^{\mathrm{c}}(\mathrm{n}=72)$ & $\mathrm{Total}_{(\mathrm{N}=216)} \mathrm{Statistic}^{\mathrm{d}} P_{\text {value }}$ \\
\hline Age (years), mean (SD); range & $\begin{array}{l}35.82(13.04) ; \\
18-72\end{array}$ & $33.11(9.74) ; 19-52$ & $\begin{array}{l}31.82(10.50) ; \\
19-58\end{array}$ & $\begin{array}{l}33.57(11.24) ; \\
18-72\end{array}$
\end{tabular}

Sex, n (\%)

Female
Male

Marital status, n (\%)

Single

Education level, n (\%)

Basic studies
Medium studies
Higher studies

Higher studies

Principal diagnosis, $n(\%)$

$\begin{array}{ll}\mathrm{MDD}^{\mathrm{f}} & 11(15) \\ \mathrm{DD}^{\mathrm{g}} & 1(1) \\ \mathrm{GAD}^{\mathrm{h}} & 26(37) \\ \mathrm{PD}^{\mathrm{i}} / \mathrm{AG}^{\mathrm{j}} & 4(6) \\ \mathrm{PD} & 2(3) \\ \mathrm{AG} & 6(9) \\ \mathrm{SAD}^{\mathrm{k}} & 15(21) \\ \text { OCD }^{1} & 3(4) \\ \text { Anxiety NOS }^{\mathrm{m}} & 3(4) \\ \text { Depression NOS }^{\mathrm{N}} & 0(0)\end{array}$

Number of comorbid disorders, $n(\%)$

0

1

MDD

DD

GAD

PD/AG

PD

AG

SAD

OCD

Anxiety NOS

Depression NOS

2

MDD and GAD

MDD and PD/AG

$\begin{array}{ll}51(72) & 51(70) \\ 20(28) & 22(30)\end{array}$

$44(62)$

23 (32)

4 (6)

1 (1)

$15(21)$

55 (78)

$1(15)$

(1)

(3)

5 (21)

(4)

(0)

32 (45)

28 (39)

18 (64)

1 (4)

2 (7)

0 (0)

0 (0)

3 (11)

4 (14)

$0(0)$

$0(0)$

0 (0)

7 (10)

2 (29)

1 (14)
41 (56)

27 (37)

5 (7)

5 (7)

12 (16)

56 (77)

9 (12)

$0(0)$

21 (29)

$6(8)$

4 (6)

$6(8)$

23 (32)

1 (1)

3 (4)

0 (0)

19 (26)

36 (49)

22 (61)

2 (6)

7 (19)

$0(0)$

$0(0)$

2 (6)

$3(8)$

$0(0)$

$0(0)$

$0(0)$

12 (16)

$3(25)$

$1(8)$
$X_{2}{ }^{2}=0.2 \quad .88$

155 (71.8)

$61(28.2)$

19 (26)

$\mathrm{N} / \mathrm{A}^{\mathrm{e}}$

.97

42 (58)

127 (58.8)

25 (35)

75 (34.7)

5 (7)

N/A

.46

3 (4)

17 (24)

44 (20.4)

$52(72)$

$163(75.5)$

N/A

.57

$16(22) \quad 36(16.7)$

$2(3)$

3 (1.4)

$24(33)$

$71(32.9)$

$6(8)$

$16(7.4)$

$3(4)$

9 (4.2)

1 (1)

13 (6.0)

16 (22)

54 (25.0)

2 (3)

$6(2.8)$

1 (1)

7 (3.2)

1 (1)

$1(0.5)$

N/A

.17

34 (47)

81 (37.5)

26 (36)

92 (42.6)

15 (57)

57 (62)

3 (12)

$6(7)$

2 (8)

11 (12)

0 (0)

$0(0.0)$

1 (4)

1 (1)

2 (8)

7 (8)

3 (11)

10 (10)

0 (0)

$0(0)$

0 (0)

$0(0)$

$0(0)$

$0(0)$

27 (12.5)

$2(29)$

7 (26)

1 (14) 


\begin{tabular}{|c|c|c|c|c|c|c|}
\hline Variable & $\operatorname{TIBP}^{\mathrm{a}}(\mathrm{n}=71)$ & $\mathrm{TIBP}+\mathrm{PA}^{\mathrm{b}}(\mathrm{n}=73)$ & $\mathrm{WL}^{\mathrm{c}}(\mathrm{n}=72)$ & Total $(\mathrm{N}=216)$ & Statistic $^{\mathrm{d}}$ & $P$ value \\
\hline MDD and PD & $1(14)$ & $1(8)$ & $2(29)$ & $4(15)$ & & \\
\hline $\mathrm{MDD}$ and $\mathrm{AG}$ & $0(0)$ & $2(17)$ & $0(0)$ & $3(11)$ & & \\
\hline MDD and OCD & $1(14)$ & $0(0)$ & $0(0)$ & $1(4)$ & & \\
\hline DD and SAD & $0(0)$ & $1(8)$ & $0(0)$ & $1(4)$ & & \\
\hline GAD and SAD & $2(29)$ & $1(8)$ & $1(14)$ & $4(15)$ & & \\
\hline GAD and AG & $0(0)$ & $2(17)$ & $0(0)$ & $2(7)$ & & \\
\hline $\mathrm{PD} / \mathrm{AG}$ and $\mathrm{SAD}$ & $0(0)$ & $0(0)$ & $1(14)$ & $1(4)$ & & \\
\hline SAD and OCD & $0(0)$ & $1(8)$ & $0(0)$ & $1(4)$ & & \\
\hline 3 & $4(6)$ & $6(8)$ & $5(7)$ & $16(7.4)$ & & \\
\hline $\mathrm{MDD}, \mathrm{GAD}$, and $\mathrm{AG}$ & $1(25)$ & $1(17)$ & $2(40)$ & $4(25)$ & & \\
\hline MDD, GAD, and SAD & $0(0)$ & $2(33)$ & $2(40)$ & $4(25)$ & & \\
\hline MDD, GAD, and OCD & $0(0)$ & $1(17)$ & $0(0)$ & $2(13)$ & & \\
\hline $\mathrm{MDD}, \mathrm{PD}$, and $\mathrm{SAD}$ & $0(0)$ & $2(33)$ & $0(0)$ & $2(13)$ & & \\
\hline MDD, PD, and OCD & $0(0)$ & $0(0)$ & $1(20)$ & $1(6)$ & & \\
\hline $\mathrm{MDD}, \mathrm{AG}$, and $\mathrm{SAD}$ & $1(25)$ & $0(0)$ & $0(0)$ & $1(6)$ & & \\
\hline MDD, SAD, and OCD & $1(25)$ & $0(0)$ & $0(0)$ & $1(6)$ & & \\
\hline GAD, PD/AG, and SAD & $1(25)$ & $0(0)$ & $0(0)$ & $1(6)$ & & \\
\hline
\end{tabular}

${ }^{\text {a} T I B P: ~ t r a n s d i a g n o s t i c ~ i n t e r n e t-b a s e d ~ p r o t o c o l . ~}$

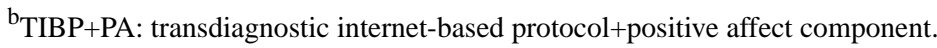

${ }^{\mathrm{c}} \mathrm{WL}$ : waiting list.

${ }^{\mathrm{d}}$ Statistic: Pearson chi-square or Fisher exact test.

${ }^{\mathrm{e}} \mathrm{N} / \mathrm{A}$ : not applicable.

${ }^{\mathrm{f}} \mathrm{MDD}$ : major depressive disorder.

${ }^{\mathrm{g}} \mathrm{DD}$ : dysthymic disorder.

${ }^{\mathrm{h}} \mathrm{GAD}$ : generalized anxiety disorder.

${ }^{\mathrm{i}} \mathrm{PD}$ : panic disorder.

${ }^{\mathrm{j}} \mathrm{AG}$ : agoraphobia.

${ }^{\mathrm{k}} \mathrm{SAD}$ : social anxiety disorder.

${ }^{l} \mathrm{OCD}$ : obsessive-compulsive disorder.

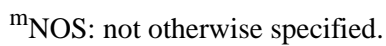

\section{Baseline Data and Participant Characteristics}

Details about participants' sociodemographic characteristics for each group at pretreatment are presented in Table 2. The results indicated that there were no significant differences between the experimental groups before treatment for any of these variables, indicating that the randomization was successful. Overall, participants' mean age was 33.57 years (SD 11.24, range $18-72)$, the majority were females $(155 / 216,71.8 \%)$, and most of them were single $(127 / 216,58.8 \%)$ and had completed or were pursuing higher studies (163/216, 75.5\%; eg, undergraduate degree studies, graduate studies or university master's degrees, or postgraduate studies or doctoral degrees).
Principal and comorbid diagnoses are presented in Table 2. Most of the participants had GAD $(71 / 216,32.9 \%)$, followed by $\operatorname{SAD}(54 / 216,25.0 \%)$ and $\operatorname{MDD}(36 / 216,16.7 \%)$. Regarding the patterns of comorbidity in the sample, $41.7 \%$ (90/216) of the participants had at least one comorbid diagnosis, with MDD being the most common comorbid disorder $(n=57)$, followed by GAD $(n=11), \operatorname{SAD}(n=10), \operatorname{AG}(n=7), D D(n=6)$, and PD $(n=1)$.

Regarding the clinical characteristics of the participants in each experimental condition at pretreatment (Table 3), no statistically significant differences were found between the groups on any of the primary and secondary outcomes. 
Table 3. Clinical characteristics of participants at pre-assessment.

\begin{tabular}{|c|c|c|c|c|c|c|}
\hline Measure & $\begin{array}{l}\operatorname{TIBP}^{\mathrm{a}}(\mathrm{n}=71) \\
\text { mean }(\mathrm{SD})\end{array}$ & $\begin{array}{l}\mathrm{TIBP}+\mathrm{PA}^{\mathrm{b}}(\mathrm{n}=73) \\
\text { mean }(\mathrm{SD})\end{array}$ & $\begin{array}{l}\mathrm{WL}^{\mathrm{c}}(\mathrm{n}=72) \\
\text { mean }(\mathrm{SD})\end{array}$ & $\begin{array}{l}\text { Total }(\mathrm{N}=216), \\
\text { mean }(\mathrm{SD})\end{array}$ & Statistic, $F(d f)$ & $P$ value \\
\hline \multicolumn{7}{|l|}{ Primary outcomes } \\
\hline BDI-II ${ }^{\mathrm{d}}$ & $25.35(11.33)$ & $29.07(11.33)$ & $26.31(12.43)$ & $26.93(11.76)$ & $1.966(2213)$ & .14 \\
\hline $\mathrm{BAI}^{\mathrm{e}}$ & $21.14(12.10)$ & $23.58(11.50)$ & $21.87(12.56)$ & $22.23(12.04)$ & $0.719(2,197)$ & .49 \\
\hline PANAS ${ }_{-}^{\mathrm{f}}$ Positive & $20.72(6.52)$ & $19.32(6.22)$ & $19.28(5.67)$ & $19.84(6.22)$ & $1.277(2213)$ & .28 \\
\hline PANAS_Negative & $30.68(7.73)$ & $31.96(8.79)$ & $28.63(9.03)$ & $30.43(8.61)$ & $2.807(2213)$ & .06 \\
\hline \multicolumn{7}{|l|}{ Secondary outcomes } \\
\hline \multicolumn{7}{|l|}{ Personality measures } \\
\hline NEO FFI ${ }^{\mathrm{g}}$ _Neuroticism & $31.54(6.65)$ & $34.11(8.18)$ & $31.39(8.20)$ & $32.36(7.78)$ & $2.853(2213)$ & .06 \\
\hline NEO FFI_Extraversion & $21.49(8.77)$ & $19.26(7.59)$ & $21.79(8.66)$ & $20.84(8.39)$ & $1.991(2213)$ & .14 \\
\hline \multicolumn{7}{|l|}{ Quality of life } \\
\hline EQ-5D ${ }^{\mathrm{h}}$ & $54.60(17.76)$ & $54.78(19.75)$ & $51.91(17.81)$ & $53.75(18.44)$ & $0.511(2197)$ & .60 \\
\hline
\end{tabular}

a TIBP: transdiagnostic internet-based protocol.

$\mathrm{b}_{\mathrm{TIBP}}+\mathrm{PA}$ : transdiagnostic internet-based protocol+positive affect component.

${ }^{\mathrm{c}} \mathrm{WL}$ : waiting list.

d BDI-II: Beck Depression Inventory-II.

e BAI: Beck Anxiety Inventory.

${ }^{f}$ PANAS: Positive and Negative Affect Schedule.

g NEO FFI: NEO Five Factor Inventory.

${ }^{\mathrm{h}}$ EQ-5D: EuroQoL-5D questionnaire.

\section{Effectiveness of the Intervention on Primary and Secondary Outcomes at Pre-Post}

\section{Primary Outcomes}

Table 4 includes descriptive statistics (ie, means and SD) for TIBP+PA, TIBP, and WL at pretreatment and posttreatment; Table 5 includes within-group and between-group effect sizes and CIs for all the primary outcome measures in the three experimental groups, based on the ITT sample.

For the three primary outcomes, within-group comparisons indicated significant pre-post reductions in the two experimental conditions, with large effect sizes for the BDI-II $(d=1.19)$ and PANAS-N $(d=1.28)$, and moderate effect sizes for the BAI $(d=0.63)$ and PANAS-P $(d=0.69)$ in the TIBP condition. In the TIBP+PA condition, the effect sizes were large for all primary outcomes $(d=1.42$, BDI-II; $d=0.91$, BAI; $d=1.27$, PANAS-P; $d=1.26$, PANAS-N). Between-group comparisons revealed that participants who received the treatment scored better at posttreatment than the WL group. Greater reductions were found in the BDI-II scores in the TIBP condition than in the WL condition (mean difference $-13.61 ; P<.001 ; d=1.18 ; 95 \% \mathrm{CI}$ -1.61 to -0.76$)$, as well as between the TIBP+PA condition and WL (mean difference $-14.31 ; P<.001 ; d=1.05 ; 95 \%$ CI
-1.46 to -0.63$)$, with large effect sizes. No differences were found between the two experimental conditions (mean difference $0.70 ; P=.76 ; d=0.10 ; 95 \% \mathrm{CI}-0.51$ to -0.31$)$. The results for BAI scores were similar to the pattern of findings for the BDI: greater reductions in the TIBP condition (mean difference -8.19; $P=.001 ; d=0.63 ; 95 \% \mathrm{CI}-1.07$ to -0.20$)$ and TIBP+PA condition (mean difference $-9.28 ; P<.001 ; d=0.68 ; 95 \% \mathrm{CI}$ -1.10 to -0.26 ), compared with WL, with medium effect sizes, and no differences between the two experimental conditions (mean difference $1.09 ; P=.65 ; d=0.05 ; 95 \% \mathrm{CI}-0.39$ to 0.49 ). Finally, patients in the TIBP condition experienced a large increase in PA (PANAS-P) compared with WL (mean difference 5.42; $P<.001 ; d=0.74 ; 95 \%$ CI 0.33 to 1.15 ) with moderate effect sizes and greater reductions in NA (PANAS-N; mean difference $-8.34 ; P<.001 ; d=0.99 ; 95 \% \mathrm{CI}-1.41$ to -0.57 ) compared with WL with large effect sizes. Participants in the TIBP+PA condition experienced the same pattern as the participants in the TIBP condition but achieving large effect sizes for both higher PA (mean difference $7.86 ; P<.001 ; d=0.90 ; 95 \%$ CI 0.49 to 1.31 ) and lower NA (mean difference $-8.32 ; P<.001 ; d=0.91$; $95 \% \mathrm{CI}-1.32$ to -0.50 ) than participants in the WL condition. No differences were found between the two experimental conditions on PA (mean difference $-2.44 ; P=.08 ; d=0.25 ; 95 \%$ CI -0.66 to 0.17 ) or NA (mean difference $-0.02 ; P=.99 ; d=0.01$; $95 \% \mathrm{CI}-0.42$ to 0.40$)$. 
Table 4. Descriptive statistics for TIBP+PA, TIBP, and WL at pretreatment and posttreatment for primary outcomes, personality measures, and quality of life measures.

\begin{tabular}{|c|c|c|c|c|c|c|}
\hline \multirow[t]{2}{*}{ Measures } & \multicolumn{2}{|c|}{$\mathrm{TIBP}+\mathrm{PA}^{\mathrm{a}}(\mathrm{n}=46)$, mean $(\mathrm{SD})$} & \multicolumn{2}{|c|}{$\operatorname{TIBP}^{\mathrm{b}}(\mathrm{n}=45)$, mean $(\mathrm{SD})$} & \multicolumn{2}{|c|}{$\mathrm{WL}^{\mathrm{c}}(\mathrm{n}=55)$, mean $(\mathrm{SD})$} \\
\hline & Pre- $T^{d}$ & Post- $\mathrm{T}^{\mathrm{e}}$ & Pre-T & Post-T & Pre-T & Post-T \\
\hline \multicolumn{7}{|l|}{ Primary outcomes } \\
\hline BDI-II ${ }^{\mathrm{f}}$ & $29.07(11.33)$ & $12.78(10.76)$ & $25.35(11.33)$ & $11.76(9.02)$ & $26.31(12.42)$ & $26.09(13.99)$ \\
\hline $\mathrm{BAI}^{\mathrm{g}}$ & $23.58(11.50)$ & $12.97(10.33)$ & $21.14(12.10)$ & $13.46(10.26)$ & $21.87(12.56)$ & $21.67(14.41)$ \\
\hline $\begin{array}{l}\text { Positive Affect subscale of the Positive and } \\
\text { Negative Affect Schedule }\end{array}$ & $19.32(6.22)$ & $27.28(9.21)$ & $20.72(6.52)$ & $25.24(7.10)$ & $19.28(5.68)$ & $19.86(7.27)$ \\
\hline $\begin{array}{l}\text { Negative Affect subscale of the Positive and } \\
\text { Negative Affect Schedule }\end{array}$ & $31.96(8.79)$ & $20.78(8.37)$ & $30.68(7.73)$ & $20.71(6.81)$ & $28.63(9.03)$ & $28.76(8.99)$ \\
\hline \multicolumn{7}{|l|}{ Secondary outcomes } \\
\hline \multicolumn{7}{|l|}{ Personality measures } \\
\hline Neuroticism subscale of the NEO FFI ${ }^{\mathrm{h}}$ & $34.11(8.18)$ & $27.67(8.37)$ & $31.54(6.65)$ & $26.64(7.83)$ & $31.39(8.20)$ & $31.71(8.56)$ \\
\hline Extraversion subscale of the NEO FFI & $19.26(7.59)$ & $24.22(7.64)$ & $21.49(8.77)$ & $24.13(8.41)$ & $21.79(8.66)$ & $19.84(10.02)$ \\
\hline \multicolumn{7}{|l|}{ Quality of life } \\
\hline EuroQoL-5D-3L questionnaire & $54.78(19.75)$ & $68.81(18.37)$ & $54.60(17.76)$ & $64.05(18.78)$ & $51.91(17.81)$ & $52.55(18.96)$ \\
\hline
\end{tabular}

${ }^{\mathrm{a}} \mathrm{TIBP}+\mathrm{PA}$ : transdiagnostic internet-based protocol + positive affect component.

${ }^{\mathrm{T}}$ TIBP: transdiagnostic internet-based protocol.

${ }^{\mathrm{c}} \mathrm{WL}$ : waiting list.

${ }^{\mathrm{d}}$ Pre-T: Pre-treatment.

${ }^{\mathrm{e}}$ Post-T: Post-treatment.

${ }^{f}$ BDI-II: Beck Depression Inventory-II.

$\mathrm{g}_{\text {BAI: Beck Anxiety Inventory. }}$

${ }^{\mathrm{h}}$ NEO FFI: NEO Five Factor Inventory. 
Table 5. Within- and between-group effect sizes and 95\% CIs.

\begin{tabular}{|c|c|c|c|c|c|c|}
\hline \multirow[t]{2}{*}{ Measures } & $\begin{array}{l}\mathrm{TIBP}+\mathrm{PA}^{\mathrm{a}}, d \\
(95 \% \mathrm{CI})\end{array}$ & $\begin{array}{l}\mathrm{TIBP}^{\mathrm{b}}, d(95 \% \\
\mathrm{CI})\end{array}$ & $\mathrm{WL}^{\mathrm{c}}, d(95 \% \mathrm{CI})$ & $\begin{array}{l}\text { TIBP+PA versus } \\
\text { TIBP, } d(95 \% \mathrm{CI})\end{array}$ & $\begin{array}{l}\text { TIBP+PA versus } \\
\mathrm{WL}, d(95 \% \mathrm{CI})\end{array}$ & $\begin{array}{l}\text { TIBP versus WL, } \\
d(95 \% \mathrm{CI})\end{array}$ \\
\hline & Pre-post & Pre-post & Pre-post & Post-T ${ }^{d}$ & Post-T & Post-T \\
\hline \multicolumn{7}{|l|}{ Primary outcomes } \\
\hline BDI-II ${ }^{\mathrm{e}}$ & $\begin{array}{l}1.42(1.09 \text { to } \\
1.76)\end{array}$ & $\begin{array}{l}1.19(0.90 \text { to } \\
1.48)\end{array}$ & $\begin{array}{l}0.02(-0.13 \text { to } \\
0.16)\end{array}$ & $\begin{array}{l}-0.10(-0.51 \text { to } \\
0.31)\end{array}$ & $\begin{array}{l}-1.05(-1.46 \text { to } \\
-0.63)\end{array}$ & $\begin{array}{l}-1.18(-1.61 \text { to } \\
-0.76)\end{array}$ \\
\hline $\mathrm{BAI}^{\mathrm{f}}$ & $\begin{array}{l}0.91(0.64 \text { to } \\
1.18)\end{array}$ & $\begin{array}{l}0.63(0.38 \text { to } \\
0.87)\end{array}$ & $\begin{array}{l}0.02(-0.12 \text { to } \\
0.15)\end{array}$ & $\begin{array}{l}0.05(-0.39 \text { to } \\
0.49)\end{array}$ & $\begin{array}{l}-0.68(-1.10 \text { to }- \\
0.26)\end{array}$ & $\begin{array}{l}-0.63(-1.07 \text { to } \\
-0.20)\end{array}$ \\
\hline $\begin{array}{l}\text { Positive Affect subscale of } \\
\text { the Positive and Negative } \\
\text { Affect Schedule }\end{array}$ & $\begin{array}{l}-1.27(-1.58 \text { to } \\
-0.95)\end{array}$ & $\begin{array}{l}-0.69(-0.92 \text { to } \\
-0.45)\end{array}$ & $\begin{array}{l}-0.01(-0.22 \text { to } \\
0.20)\end{array}$ & $\begin{array}{l}-0.25(-0.66 \text { to } \\
0.17)\end{array}$ & $\begin{array}{l}0.90(0.49 \text { to } \\
1.31)\end{array}$ & $\begin{array}{l}0.74(0.33 \text { to } \\
1.15)\end{array}$ \\
\hline $\begin{array}{l}\text { Negative Affect subscale } \\
\text { of the Positive and Nega- } \\
\text { tive Affect Schedule }\end{array}$ & $\begin{array}{l}1.26(0.94 \text { to } \\
1.57)\end{array}$ & $\begin{array}{l}1.28(0.96 \text { to } \\
1.60)\end{array}$ & $\begin{array}{l}-0.04(-0.22 \text { to } \\
0.14)\end{array}$ & $\begin{array}{l}-0.01(-0.42 \text { to } \\
0.40)\end{array}$ & $\begin{array}{l}-0.91(-1.32 \text { to } \\
-0.50)\end{array}$ & $\begin{array}{l}-0.99(-1.41 \text { to } \\
-0.57)\end{array}$ \\
\hline \multicolumn{7}{|l|}{ Secondary outcomes } \\
\hline \multicolumn{7}{|l|}{ Personality measures } \\
\hline $\begin{array}{l}\text { Neuroticism subscale } \\
\text { of the NEO FFI }\end{array}$ & $\begin{array}{l}0.78(0.51 \text { to } \\
1.05)\end{array}$ & $\begin{array}{l}0.73(0.50 \text { to } \\
0.96)\end{array}$ & $\begin{array}{l}0.04(-0.22 \text { to } \\
0.20)\end{array}$ & $\begin{array}{l}-0.12(-0.54 \text { to } \\
0.29)\end{array}$ & $\begin{array}{l}-0.47(-0.87 \text { to } \\
-0.08)\end{array}$ & $\begin{array}{l}0.61(-1.01 \text { to } \\
-0.21)\end{array}$ \\
\hline $\begin{array}{l}\text { Extraversion subscale } \\
\text { of the NEO FFI }\end{array}$ & $\begin{array}{l}0.65(-0.88 \text { to } \\
-0.42)\end{array}$ & $\begin{array}{l}0.30(-0.45 \text { to } \\
-0.14)\end{array}$ & $\begin{array}{l}0.22(0.07 \text { to } \\
0.37)\end{array}$ & $\begin{array}{l}-0.01(-0.42 \text { to } \\
0.40)\end{array}$ & $\begin{array}{l}0.48(0.08 \text { to } \\
0.88)\end{array}$ & $\begin{array}{l}0.46(0.06 \text { to } \\
0.86)\end{array}$ \\
\hline \multicolumn{7}{|l|}{ Quality of life } \\
\hline $\begin{array}{l}\text { EuroQoL-5D-3L } \\
\text { questionnaire }\end{array}$ & $\begin{array}{l}0.70(-0.97 \text { to } \\
-0.43)\end{array}$ & $\begin{array}{l}0.53(-0.80 \text { to } \\
-0.25)\end{array}$ & $\begin{array}{l}0.04(-0.21 \text { to } \\
0.14)\end{array}$ & $\begin{array}{l}-0.25(-0.70 \text { to } \\
0.19)\end{array}$ & $\begin{array}{l}0.86(0.44 \text { to } \\
1.29)\end{array}$ & $\begin{array}{l}0.60(0.17 \text { to } \\
1.04)\end{array}$ \\
\hline
\end{tabular}

${ }^{\mathrm{a}}$ TIBP+PA: transdiagnostic internet-based protocol+positive affect component.

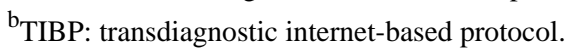

${ }^{\mathrm{c}} \mathrm{WL}$ : waiting list.

${ }^{\mathrm{d}}$ Post-T: posttreatment.

e BDI-II: Beck Depression Inventory-II.

f BAI: Beck Anxiety Inventory.

gEO FFI: NEO Five Factor Inventory.

\section{Secondary Outcomes}

Table 4 includes descriptive statistics (ie, mean and SD) for TIBP+PA, TIBP, and WL at pretreatment and posttreatment, and Table 5 includes within-group and between-group effect sizes and CIs for secondary outcomes related to personality and quality of life measures in the three experimental groups based on the ITT sample.

Regarding personality measures, within-group comparisons indicated a significant pre-to-post reduction in neuroticism in the two experimental conditions, with moderate effect sizes in NEO Five Factor Inventory (NEO FFI)-Neuroticism $(d=0.73$, TIBP; $d=0.78$, TIBP+PA), and a significant pre-to-post increase in extraversion in the two experimental conditions, with a small effect size in the TIBP condition $(d=0.30)$ and a moderate effect size in the TIBP+PA condition $(d=0.65)$. In the WL control group, significant changes with small effect sizes were also found on NEO FFI-Extraversion $(d=0.22)$. Between-group comparisons revealed that participants who received the treatment scored better at posttreatment on NEO FFI-Neuroticism in both intervention groups compared with the WL group, with moderate effect sizes $(d=0.61$, TIBP; $d=0.47$, TIBP+PA). NEO FFI-Extraversion showed better scores with small effect sizes in both intervention conditions $(d=0.46$, TIBP; $d=0.48$, TIBP+PA) than WL. No statistically significant differences were found between the two experimental conditions for the personality measures.

Finally, quality of life measures (ie, EuroQoL-5D Questionnaire; EQ-5D) showed a significant time effect $\left(F_{1,152.98}=32.98\right.$; $P<.001)$. Both intervention groups experienced significant improvements in quality of life posttreatment, and this improvement was not found in the WL control group. Within-group comparisons indicated moderate effect sizes in the TIBP condition $(d=0.53)$, moderate effect sizes in the TIBP+PA condition $(d=0.70)$, and nonsignificant changes in the WL control group. Between-group comparisons revealed that participants who received the treatment (with or without the specific component to upregulate PA) scored higher on quality of life at posttreatment, compared with the WL, with moderate effect sizes in the TIBP condition $(d=0.60)$ and large effect sizes in the TIBP+PA condition $(d=0.86$; Table 4 for details). The differences between the two treatment groups were not statistically significant. 


\section{Expectations and Satisfaction}

Table 6 lists the results for the two interventions groups. Items for expectations and satisfaction were rated from 0 (strongly disagree) to 10 (strongly agree), covering how logical the treatment seemed, to what extent it could satisfy the patient, whether it could be used to treat other psychological problems, and its usefulness for the patient's specific problem. Before the treatment, all the scores were high. The analysis revealed statistically significant differences between the two conditions on expectations about the treatment: before treatment, participants in the TIBP+PA condition considered the treatment more logical $\left(\mathrm{F}_{1,89}=4.49 ; P=.03\right)$, more satisfactory $\left(\mathrm{F}_{1,89}=6.29\right.$;
$P=.01)$, more recommendable to others $\left(\mathrm{F}_{1,89}=6.15 ; P=.01\right)$, and more useful for other psychological problems $\left(\mathrm{F}_{1,89}=7.38\right.$; $P=.008)$ than the TIBP participants did. In addition, at posttreatment, participants' satisfaction scores were also high. The analysis revealed statistically significant differences between the two conditions on satisfaction: after treatment, participants in the TIBP+PA condition considered the treatment more satisfactory $\left(\mathrm{F}_{1,89}=4.10 ; P=.04\right)$, recommendable to others $\left(\mathrm{F}_{1,89}=6.79 ; P=.01\right)$, more useful for other psychological problems $\left(\mathrm{F}_{1,89}=5.13 ; P=.02\right)$, and more useful for the patient $\left(\mathrm{F}_{1,89}=5.91 ; P=.01\right)$ than participants in the TIBP condition did.

Table 6. Means and SDs for expectations and satisfaction.

\begin{tabular}{|c|c|c|c|c|}
\hline \multirow[t]{2}{*}{ Statements } & \multicolumn{2}{|c|}{ Expectations } & \multicolumn{2}{|c|}{ Satisfaction } \\
\hline & $\mathrm{n}$ & Mean (SD) & $\mathrm{n}$ & Mean (SD) \\
\hline \multicolumn{5}{|c|}{ How logical do you think this treatment is? } \\
\hline Total sample & 91 & $8.21(1.55)$ & 91 & $8.21(1.67)$ \\
\hline TIBP $^{\mathrm{a}}$ & 45 & $7.87(1.71)$ & 45 & $8.07(1.68)$ \\
\hline $\mathrm{TIBP}+\mathrm{PA}^{\mathrm{b}}$ & 46 & $8.54(1.31)$ & 46 & 8.35 (1.66) \\
\hline \multicolumn{5}{|c|}{ How satisfied are you with the treatment received? } \\
\hline Total sample & 91 & $8.21(1.75)$ & 91 & $7.63(2.02)$ \\
\hline TIBP & 45 & $7.76(1.86)$ & 45 & $7.20(2.04)$ \\
\hline $\mathrm{TIBP}+\mathrm{PA}$ & 46 & $8.65(1.54)$ & 46 & $8.04(1.93)$ \\
\hline \multicolumn{5}{|c|}{ To what extent do you feel confident about recommending this treatment to a friend who has the same problems? } \\
\hline Total sample & 91 & $8.36(1.77)$ & 91 & $8.01(2.12)$ \\
\hline TIBP & 45 & $7.91(1.95)$ & 45 & $7.44(2.32)$ \\
\hline $\mathrm{TIBP}+\mathrm{PA}$ & 46 & $8.80(1.45)$ & 46 & $8.57(1.75)$ \\
\hline \multicolumn{5}{|c|}{ Do you think this treatment could be useful for treating other psychological disorders? } \\
\hline Total sample & 91 & $8.03(1.72)$ & 91 & $7.88(1.76)$ \\
\hline TIBP & 45 & $7.56(1.79)$ & 45 & $7.47(1.89)$ \\
\hline $\mathrm{TIBP}+\mathrm{PA}$ & 46 & $8.50(1.52)$ & 46 & $8.28(1.53)$ \\
\hline \multicolumn{5}{|c|}{ To what extent do you think the treatment was helpful to you? } \\
\hline Total sample & 91 & $7.44(1.93)$ & 91 & $7.30(2.07)$ \\
\hline TIBP & 45 & $7.13(1.87)$ & 45 & $6.78(2.00)$ \\
\hline $\mathrm{TIBP}+\mathrm{PA}$ & 46 & $7.74(1.97)$ & 46 & $7.80(2.03)$ \\
\hline
\end{tabular}

${ }^{\mathrm{a}}$ TIBP: transdiagnostic internet-based protocol.

${ }^{\mathrm{b}}$ TIBP+PA: transdiagnostic internet-based protocol+positive affect component.

\section{Reliable and Clinically Significant Change}

On the basis of the two criteria proposed by Jacobson and Truax to estimate clinically meaningful improvement, patients were classified as recovered, improved, stable, or deteriorated at posttreatment. The RCI has been expressed graphically to facilitate a more intuitive interpretation (Figures 2-5). At posttreatment, statistically significant differences were found between the three conditions in these percentages for all primary outcomes: BDI-II $(P<.001)$, BAI $(P<.001)$, PANAS-P $(P=.001)$, and PANAS-N $(P<.001)$. Overall, participants who received the transdiagnostic internet-based interventions showed a higher percentage of recovery compared with WL, which obtained high percentages of reliable deterioration on all the primary outcomes. No statistically significant differences were found between TIBP+PA and TIBP (BDI-II, $P=.59$; BAI, $P=.67$; PANAS-P, $P=.59$; and PANAS-N, $P=.59$ ). 
Figure 2. Percentages of participants recovered, improved, stable, and deteriorated on depression scores (Beck Depression Inventory-II) in transdiagnostic internet-based protocol+positive affect component (inner circle), transdiagnostic internet-based protocol (middle circle), and waiting list (outer circle).

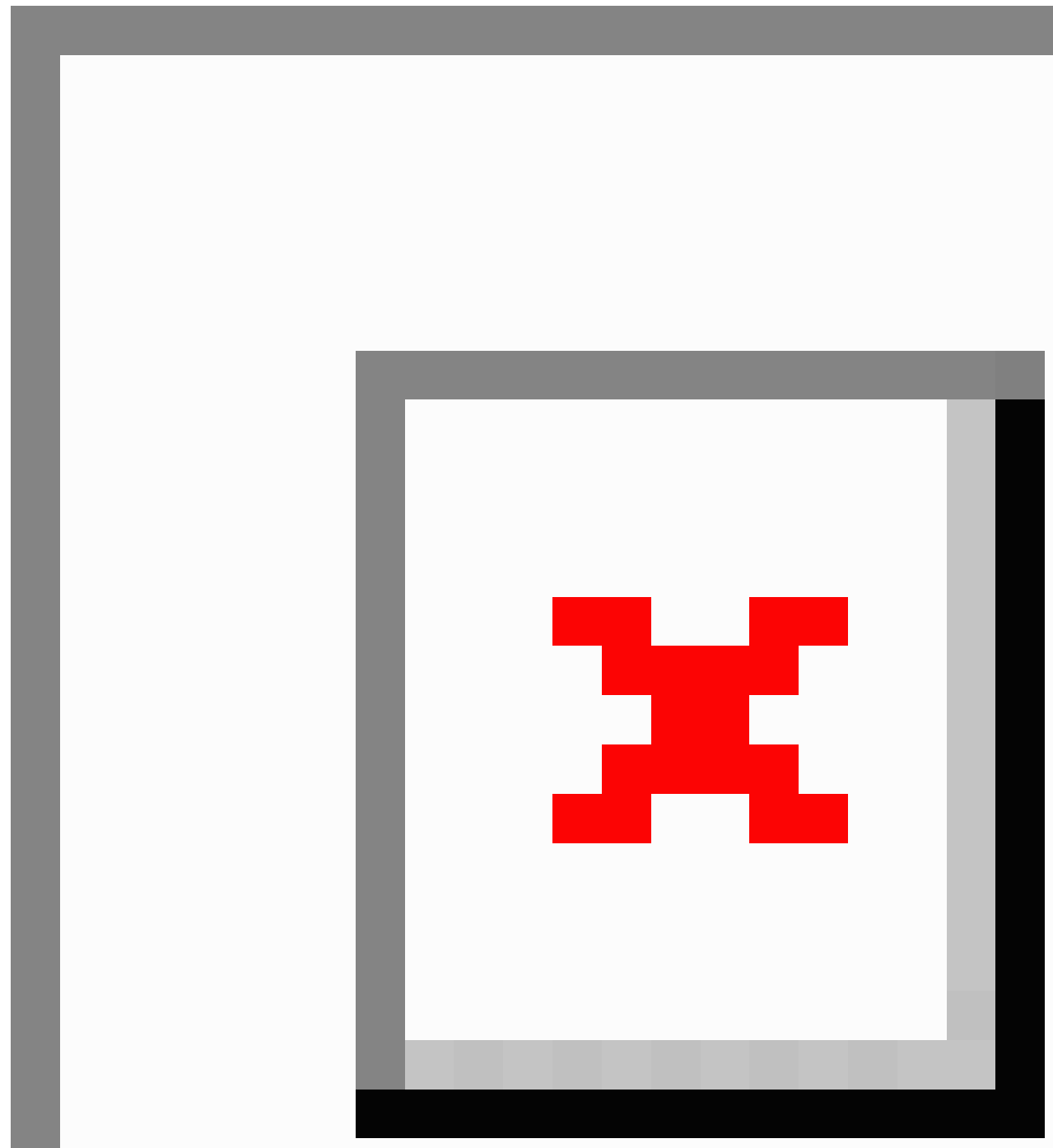


Figure 3. Percentages of participants recovered, improved, stable, and deteriorated on depression scores (Beck Anxiety Inventory) in transdiagnostic internet-based protocol+positive affect component (inner circle), transdiagnostic internet-based protocol (middle circle), and waiting list (outer circle).

\section{Pre-post}

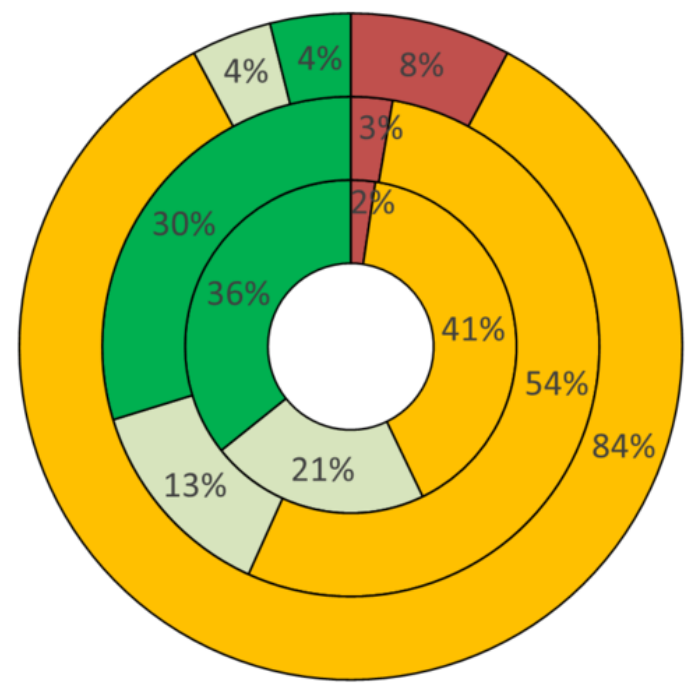

$\square$ Deteriorated

$\square$ Stable

$\square$ Improved

Recovered

Figure 4. Percentages of participants recovered, improved, stable, and deteriorated on depression scores (Positive and Negative Affect Schedule_Positive subscale) in transdiagnostic internet-based protocol+positive affect component (inner circle), transdiagnostic internet-based protocol (middle circle), and waiting list (outer circle).

\section{Pre-post}

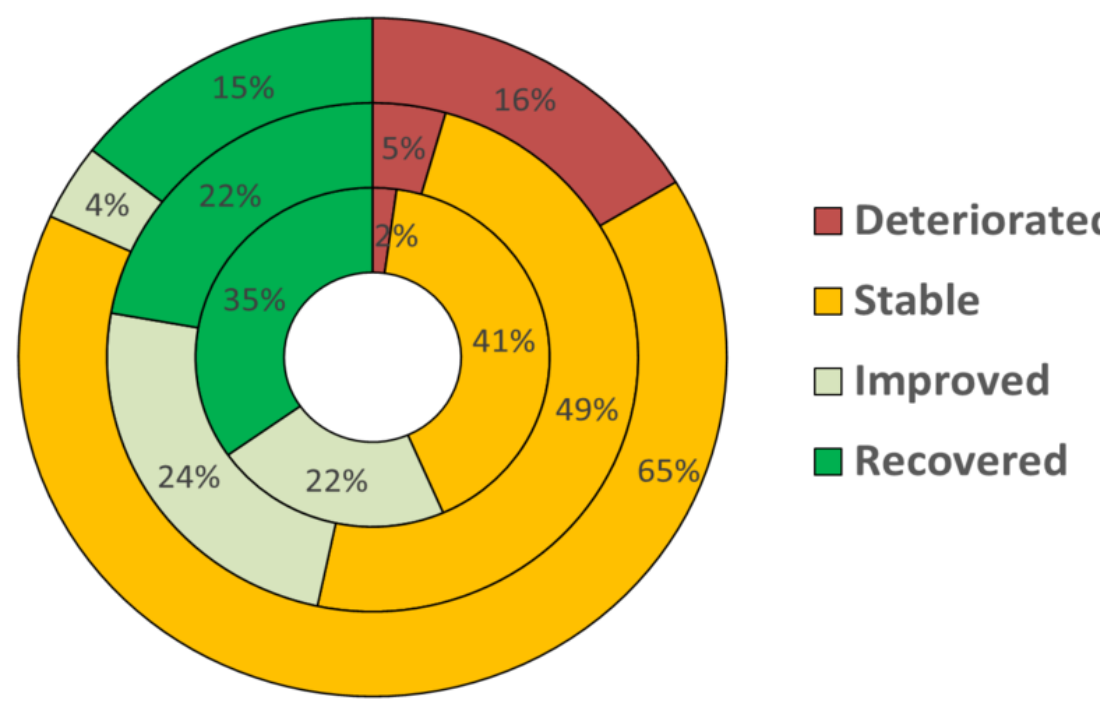


Figure 5. Percentages of participants recovered, improved, stable, and deteriorated on depression scores (Positive and Negative Affect Schedule_Negative subscale) in transdiagnostic internet-based protocol+positive affect component (inner circle), transdiagnostic internet-based protocol (middle circle), and waiting list (outer circle).

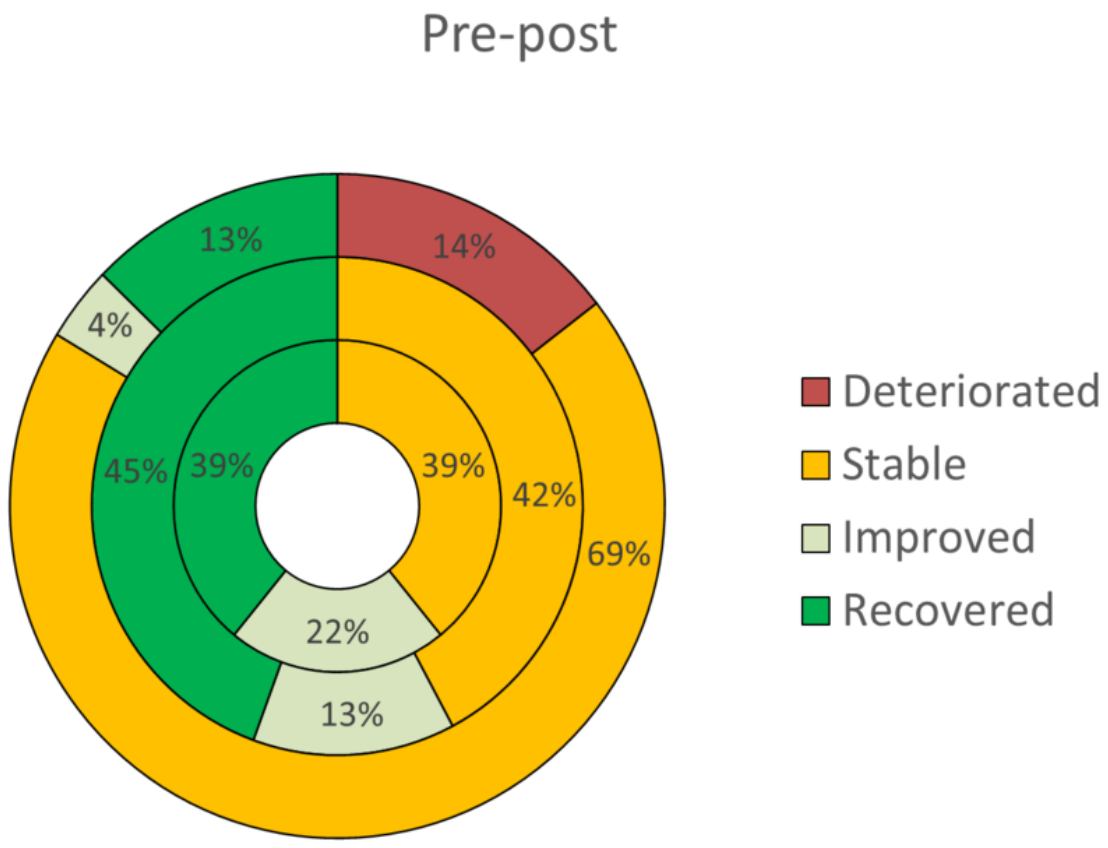

\section{Discussion}

\section{Principal Findings}

The main objective of this study was to test the efficacy of a transdiagnostic internet-based psychological treatment protocol, with and without a specific component to upregulate PA, versus a WL control group, for individuals from a community sample with one or more ED diagnoses. The results showed that on the primary outcome measures, there was a significant time effect, with medium (BAI and PANAS-P) to large effect sizes (BDI-II and PANAS-N) in the TIBP condition and large effect sizes on all measures in the TIBP+PA condition. In the WL group, the effect size was minimal. These results are comparable with those reported in other transdiagnostic trials in which effect sizes are larger for depression than for anxiety and higher for PANAS-P than for PANAS-N [13]. A possible explanation for the larger effects for depression than for anxiety could be that the therapeutic techniques more related to the treatment of anxiety disorders (ie, consequences of emotional avoidance, emotion-driven behaviors, and interoceptive and situational exposure) are presented near the end of the treatment protocol (modules from 8 to 11). Patients are evaluated clinically shortly after these modules, and consequently, they have less time to practice them. Likewise, the effects for PA were larger in the TIBP+PA condition $(d=1.27)$ than in the TIBP condition $(d=0.69)$. This result is consistent with the fact that this study includes a specific component to upregulate PA, which places greater emphasis on positive experiences. One of the aims of the intervention is to teach patients the adaptive role of both positive and negative emotions, without the need to suppress or avoid them. Nevertheless, future studies based on mediational analyses will allow a better understanding of whether PA and
NA would mediate the impact of treatment on therapy outcomes (ie, depression and anxiety). As predicted, both protocol modalities led to significantly greater reductions (relative to the WL) in depression and anxiety, as well as significant decreases in NA and increases in PA measures, suggesting that web-based transdiagnostic treatment was effective in treating EDs.

On the secondary outcomes (NEO FFI and EuroQoL-5D questionnaire, EQ-5D), the analysis also revealed a significant change from pre- to posttreatment. The effect sizes were medium for both variables in both intervention groups (except for Extraversion, which was smaller in the TIBP condition). In the WL group, small effect sizes were also found for Extraversion, showing that participants in this group experienced significantly lower levels of extraversion after the waiting period. Between-group comparisons revealed that participants who received the treatment scored better on the measures at posttreatment compared with the WL group. These findings contribute to the study of the malleability of neuroticism proposed by Barlow [86], who suggests that personality dimensions may be malleable over time. In this study, some strategies were proposed to modify PA (extraversion), and although significant effects were found between the two intervention groups and the WL group, further research is needed on this topic to explore the effect of this specific component on increasing well-being and PA. Along these lines, Barlow's team conducted an RCT that evaluated changes in PA in cognitive-behavioral treatments for anxiety disorders, showing that PA is a malleable construct and can be influenced by CBT [87].

The second aim of this study was to assess the effects of the component designed to upregulate PA, with the hypothesis that 
the TIBP+PA condition would significantly outperform the TIBP condition on the PA measures. This study found no significant differences between the two treatment conditions on PA measures. This may be due to the fact that participants improved throughout the course of the treatment, decreasing negative symptoms and increasing their PA, even if they had not seen the last four modules with the specific component to upregulate PA. Therefore, future studies will be needed to reach a deeper understanding of the relationship between treatments that include PA components and changes in PA measures.

Another objective of the study was to study patients' acceptance of the program developed to apply the treatment protocol over the internet with minimal support from clinicians. The overall expectations and satisfaction expressed by the participants in the two intervention groups were high, and both protocols were well accepted. However, the analysis revealed higher levels of expectations and satisfaction in the TIBP+PA condition. This may be due to the number of modules included in this condition (16) in comparison with the modules in the TIBP condition (12), although participants in the intervention groups did not know the content of those four additional modules. This result may be influenced by the role of expectations before and during a web-based psychological intervention, which is consistent with the literature showing that treatment expectations became more favorable over time [88]. Regarding the reliable change index, significant improvements were found in the two treatment conditions compared with the WL group. Overall, participants who received the transdiagnostic internet-based interventions showed higher recovery percentages and less deterioration compared with the WL group.

This study had a dropout rate of $38.9 \%$ (86/216). Some studies in the literature have indicated dropout rates of approximately $30 \%$ in computerized CBT programs [47]. However, this issue deserves special attention because it depends on how it is conceptualized. On the one hand, the definition of attrition differs and can be understood as premature termination [89], (non)persistence [90], (non)adherence, or the extent to which an individual is exposed to the content of an intervention [91]. In this study, only participants who completed all the treatment modules were considered completers, whereas the rest were treated as dropouts, although in other studies, only participants who completed a percentage of the modules were considered completers [92,93]. On the other hand, adherence to internet-based interventions is associated with the type of guidance, achieving $28 \%$ nonadherence when therapist-guided, and $38 \%$ when administrative support is given [94]. This study combined human and ICT support, reaching a 36.8\% (53/144) dropout rate in the treatment conditions; therefore, these results are not far from those found in the existing literature on internet-based interventions. However, further research on attrition is needed to better design internet-based treatments and increase retention. The existing literature has indicated an important relationship between the support provided to the participants and adherence to the program. Indeed, this aspect has great relevance in the literature on internet-based interventions $[95,96]$. Therefore, if this type of intervention is carried out on a large scale in the community, as in this study, a fundamental factor to consider is the type and amount of support to provide, which would be consistent with the study of the balance between the benefits and resources involved in providing human support in internet-based interventions. Technologies play a central role in this aspect because part of the support can be provided automatically through technological devices. In an attempt to understand this issue, our research group conducted a qualitative study to determine why patients dropped out of the web-based transdiagnostic program for EDs (TIBP) [97], with the results emphasizing the lack of individualization of the treatment or the lack of support (ie, the lack of affective and personal contact with the therapist). In this regard, future studies should develop personalized treatments to address patients' specific needs and increase adherence rates. There are some useful strategies for personalizing treatments, such as selecting certain treatment components to better fit the patient's symptoms or lowering the number of sessions required to successfully treat an individual's symptoms. One strategy implies personalizing the treatment to a specific presentation, that is, by selecting the treatment components that best fit the specific set of symptoms or weaknesses shown by each patient [10], thereby lowering the number of sessions required to successfully treat an individual's symptoms. Another example is the study by Carl et al [98]. In this study, the authors presented a module for the regulation of PA that can be added to the treatment once they have completed the UP modules, thus personalizing the treatment for patients who show deficits in positive emotions at posttreatment.

This study has several strengths. First, it presents a novel focus in the field of transdiagnostic treatments. To the best of our knowledge, this is the first study of a transdiagnostic internet-based treatment for EDs with a specific component to upregulate PA. Overall, the findings indicate that EDs can be effectively treated with a transdiagnostic intervention via the internet, in addition to improving depression, anxiety, and quality of life measures. Regarding PA measures, promising effects were found, but more research is needed to study the role of positive emotions in the construction of psychological strengths $[99,100]$ from a transdiagnostic perspective $[42,101]$. Moreover, this study included a large sample of people from a community sample, representing a heterogeneous population with EDs that does not receive primary or specialized care, with or without the presence of comorbidities. Thus, the transdiagnostic protocol represents a successful approach to the treatment of multiple disorders in a parsimonious manner [102]. Participants in the study seemed to be interested in the use of adaptive emotion regulation strategies, regardless of whether they were related to their own difficulty, which is the basis of transdiagnostic proposals. These interventions emphasize the essential processes underlying different disorders and the use of core higher-order strategies that eliminate the need for multiple diagnosis-specific manuals [103]. Moreover, the internet-based format of this transdiagnostic protocol facilitates the availability and administration of the program to provide support to anyone in need.

\section{Limitations}

This study also has some limitations. The most important is the different number of modules in the two protocols (TIBP condition: 12 modules; TIBP+PA condition: 16 modules). The 
TIBP condition had more time between the last module and postassessment than the TIBP+PA condition. However, the TIBP+PA condition had more modules. Postassessment took place at the end of module 12 or 16 . These aspects may have influenced the results. In an attempt to control this, equal time (ie, a maximum period of 18 weeks from randomization to posttreatment evaluation) was given to all participants to allow them to use the program as much as they desired throughout the whole process. However, future studies should show that the differential effect of the PA component is not simply because of the larger number of modules in the protocol. This leads to the importance of benchmarking based on previous transdiagnostic internet-based interventions with regard to effect sizes or the length of these interventions. This study coincides with previous similar transdiagnostic interventions that also obtained large effect sizes for depression $(g=0.84)$ and medium effect sizes for anxiety $(g=0.78)$, with a treatment length ranging from 6 to 10 sessions [18]. Furthermore, focusing on PA measures, it is important to mention that this study obtained larger effect sizes for PA, both for within- and betweencomparisons (TIBP+PA, $d=1.27$; TIBP+PA vs WL, $d=0.90$ ) than other transdiagnostic interventions [13,14,50-53]. Another limitation of the study, shared with other transdiagnostic interventions, is that although they are called transdiagnostic treatments, they are based on discrete diagnostic categories (ie, DSM-IV). Future research should study the mechanistically transdiagnostic principles, that is, the underlying mechanisms that account for the occurrence of specific symptoms to include them in both assessments and transdiagnostic interventions. Some examples of transdiagnostic mechanisms that have been found to play a fundamental role in EDs are intolerance to uncertainty [104], rumination [105], perfectionism [106], or thought suppression [107]. Among these processes, neuroticism has been strongly associated with both anxiety and depressive disorders [86,108]. In addition, attrition rates were higher in both treatment conditions (TIBP: 26/71, 37\%; TIBP+PA: 27/73, $37 \%$ ) than in the WL condition $(17 / 72,24 \%)$. However, attrition rates of $30 \%$ to $35 \%$ are commonly observed in internet-based interventions [47]. Furthermore, although we consider that the sample of this study is quite representative, future research should focus on improving the mental health of less reachable groups such as older people, people with low income or lower educational level, and/or people residing outside urban areas (ie, rural populations). Moreover, it would also be important to collect data on certain demographic variables such as race, ethnicity, and sexual orientation in future trials. Transdiagnostic treatments that are socioculturally adapted for such groups could be a potential solution to effectively reach a larger number of people in need of psychological help.

Finally, follow-up data were not included in this study because we are still in the recruiting process, and we wanted to promptly provide the results because of the importance of the issue. The long-term effects of this intervention will be presented in further research.

\section{Conclusions}

In summary, the results show the efficacy of a transdiagnostic internet-based psychological treatment protocol for individuals from a community sample with EDs. These findings show that this web-based transdiagnostic treatment improved the clinical situation of the participants, providing them with tools and strategies to face problems and difficulties more effectively. Future lines of research should carry out dismantling designs to determine the active components of the protocol, especially the contribution of the PA modules, and analyze the effectiveness of web-based treatment in other populations, such as primary care centers. Furthermore, the existing techniques and strategies to improve PA require further study to determine which ones are more effective and should be included as specific components to upregulate PA in current psychological interventions. This study includes some specific strategies to promote psychological strengths and enhance positive mood. However, it is important for future studies to explore more deeply the effect of these and other strategies on patients with EDs to directly build positive resources to counteract NA. Undoubtedly, future research will have to determine whether it is beneficial to include these components designed to enhance PA, which components are necessary for whom, and how they should be applied.

Furthermore, future research should focus on the possibility of developing treatment components aimed at altering, modifying, or varying vulnerability, a key aspect of transdiagnostic perspectives. This might be possible with strategies for modifying PA, but there are other fundamental factors that influence mental health and well-being. For example, a large body of literature has highlighted the importance of accurate perceptions of reality in psychological health, such as positive illusions or positive self-evaluations, perceptions of control or mastery, and unrealistic optimism [109,110]. In addition, there is evidence for the relationship between psychological flexibility and well-being, suggesting that being psychologically flexible has benefits for executive functioning, default mental states, and personality dimensions such as neuroticism [111]. Psychological flexibility has been considered a protective factor in improving physical health, mental health, and well-being [112]. Hence, there is growing interest in constructs such as pragmatic prospection, that is, thinking about a future with desired outcomes and avoiding undesired ones [113] or openness to the future characterized by PA toward the future [114]. This body of knowledge opens up the possibility of finding new strategies to improve the efficiency and effectiveness of future transdiagnostic treatment protocols for EDs as a way to more effectively address temperament vulnerabilities, that is, the core aspects of these disorders.

\section{Acknowledgments}

This study was funded by the Ministry of Economy and Competitiveness (Spain; PSI2014-54172-R), a PhD grant from the Ministry of Economy and Competitiveness (FPI-MINECO; BES-2015-072360), and CIBER Fisiopatología de la Obesidad y Nutrición-ISCIII CB06/03/0052. 


\section{Conflicts of Interest}

None declared.

\section{Multimedia Appendix 1}

Description of the positive affect modules.

[DOC File, 38 KB-Multimedia Appendix 1]

\section{Multimedia Appendix 2}

CONSORT-eHEALTH checklist (V 1.6.1).

[PDF File (Adobe PDF File), 1638 KB-Multimedia Appendix 2]

\section{References}

1. Bullis JR, Boettcher H, Sauer - Zavala S, Farchione TJ, Barlow DH. What is an emotional disorder? A transdiagnostic mechanistic definition with implications for assessment, treatment, and prevention. Clin Psychol Sci Pract 2019 Mar 14;26(2):e12278. [doi: 10.1111/cpsp.12278]

2. Kessler RC, Chiu WT, Demler O, Merikangas KR, Walters EE. Prevalence, severity, and comorbidity of 12-month DSM-IV disorders in the National Comorbidity Survey Replication. Arch Gen Psychiatry 2005 Jun;62(6):617-627 [FREE Full text] [doi: 10.1001/archpsyc.62.6.617] [Medline: 15939839]

3. Nathan P, Gorman J. A Guide to Treatments That Work. In: 4th Edition. United States of America: Oxford University Press; 2015.

4. Kazdin AE, Blase SL. Rebooting Psychotherapy Research and Practice to Reduce the Burden of Mental Illness. Perspectives on Psychological Science 2011 Feb 03;6(1):21-37 [FREE Full text] [doi: 10.1177/1745691610393527]

5. Ellard KK, Fairholme CP, Boisseau CL, Farchione TJ, Barlow DH. Unified Protocol for the Transdiagnostic Treatment of Emotional Disorders: Protocol Development and Initial Outcome Data. Cognitive and Behavioral Practice 2010 Feb;17(1):88-101. [doi: 10.1016/j.cbpra.2009.06.002]

6. McHugh R, Barlow D. The dissemination and implementation of evidence-based psychological treatments: A review of current efforts. Am Psychol 2010;65(2):73-84 [FREE Full text] [doi: 10.1037/a0018121]

7. Barlow DH, Allen LB, Choate ML. Toward a unified treatment for emotional disorders. Behavior Therapy 2004 Mar;35(2):205-230. [doi: 10.1016/S0005-7894(04)80036-4]

8. Brown TA, Barlow DH. A proposal for a dimensional classification system based on the shared features of the DSM-IV anxiety and mood disorders: Implications for assessment and treatment. Psychological Assessment 2009;21(3):256-271. [doi: $10.1037 / \mathrm{a} 0016608]$

9. Aldao A, Nolen-Hoeksema S, Schweizer S. Emotion-regulation strategies across psychopathology: A meta-analytic review. Clinical Psychology Review 2010 Mar;30(2):217-237. [doi: 10.1016/j.cpr.2009.11.004]

10. Sauer-Zavala S, Cassiello-Robbins C, Ametaj AA, Wilner JG, Pagan D. Transdiagnostic Treatment Personalization: The Feasibility of Ordering Unified Protocol Modules According to Patient Strengths and Weaknesses. Behav Modif 2018 May 10;43(4):518-543. [doi: 10.1177/0145445518774914]

11. Norton PJ, Paulus DJ. Toward a Unified Treatment for Emotional Disorders: Update on the Science and Practice. Behav Ther 2016 Nov;47(6):854-868. [doi: 10.1016/j.beth.2015.07.002] [Medline: 27993337]

12. Barlow DH, Farchione TJ, Bullis JR, Gallagher MW, Murray-Latin H, Sauer-Zavala S, et al. The Unified Protocol for Transdiagnostic Treatment of Emotional Disorders Compared With Diagnosis-Specific Protocols for Anxiety Disorders: A Randomized Clinical Trial. JAMA Psychiatry 2017 Aug 02:-. [doi: 10.1001/jamapsychiatry.2017.2164] [Medline: 28768327]

13. Farchione TJ, Fairholme CP, Ellard KK, Boisseau CL, Thompson-Hollands J, Carl JR, et al. Unified Protocol for Transdiagnostic Treatment of Emotional Disorders: A Randomized Controlled Trial. Behavior Therapy 2012 Sep;43(3):666-678. [doi: 10.1016/j.beth.2012.01.001]

14. Bullis JR, Fortune MR, Farchione TJ, Barlow DH. A preliminary investigation of the long-term outcome of the Unified Protocol for Transdiagnostic Treatment of Emotional Disorders. Comprehensive Psychiatry 2014 Nov;55(8):1920-1927. [doi: 10.1016/i.comppsych.2014.07.016]

15. Carl JR, Gallagher MW, Sauer-Zavala SE, Bentley KH, Barlow DH. A preliminary investigation of the effects of the unified protocol on temperament. Comprehensive Psychiatry 2014 Aug;55(6):1426-1434. [doi: 10.1016/j.comppsych.2014.04.015]

16. Reinholt N, Krogh J. Efficacy of Transdiagnostic Cognitive Behaviour Therapy for Anxiety Disorders: A Systematic Review and Meta-Analysis of Published Outcome Studies. Cognitive Behaviour Therapy 2014 Mar 19;43(3):171-184. [doi: 10.1080/16506073.2014.897367]

17. Newby JM, McKinnon A, Kuyken W, Gilbody S, Dalgleish T. Systematic review and meta-analysis of transdiagnostic psychological treatments for anxiety and depressive disorders in adulthood. Clin Psychol Rev 2015 Aug;40:91-110 [FREE Full text] [doi: 10.1016/j.cpr.2015.06.002] [Medline: 26094079] 
18. Newby JM, Twomey C, Yuan LSS, Andrews G. Transdiagnostic computerised cognitive behavioural therapy for depression and anxiety: A systematic review and meta-analysis. J Affect Disord 2016 Jul 15;199:30-41. [doi: 10.1016/j.jad.2016.03.018] [Medline: 27060430]

19. Păsărelu CR, Andersson G, Bergman NL, Dobrean A. Internet-delivered transdiagnostic and tailored cognitive behavioral therapy for anxiety and depression: a systematic review and meta-analysis of randomized controlled trials. Cogn Behav Ther 2017 Jan;46(1):1-28. [doi: 10.1080/16506073.2016.1231219] [Medline: 27712544]

20. Pearl SB, Norton PJ. Transdiagnostic versus diagnosis specific cognitive behavioural therapies for anxiety: A meta-analysis. J Anxiety Disord 2017 Mar;46:11-24. [doi: 10.1016/j.janxdis.2016.07.004] [Medline: 27466074]

21. Clark DA, Taylor S. The Transdiagnostic Perspective on Cognitive-Behavioral Therapy for Anxiety and Depression: New Wine for Old Wineskins? J Cogn Psychother 2009 Feb 01;23(1):60-66. [doi: 10.1891/0889-8391.23.1.60]

22. Sakiris N, Berle D. A systematic review and meta-analysis of the Unified Protocol as a transdiagnostic emotion regulation based intervention. Clinical Psychology Review 2019 Aug;72:101751. [doi: 10.1016/j.cpr.2019.101751]

23. Weinstock LM, Whisman MA. Neuroticism as a common feature of the depressive and anxiety disorders: A test of the revised integrative hierarchical model in a national sample. J Abnorm Psychol 2006;115(1):68-74. [doi: 10.1037/0021-843x.115.1.68]

24. Clark LA, Watson D, Mineka S. Temperament, personality, and the mood and anxiety disorders. J Abnorm Psychol 1994;103(1):103-116. [doi: 10.1037/0021-843x.103.1.103]

25. Kasch KL, Rottenberg J, Arnow BA, Gotlib IH. Behavioral activation and inhibition systems and the severity and course of depression. J Abnorm Psychol 2002;111(4):589-597. [doi: 10.1037/0021-843x.111.4.589]

26. Campbell-Sills L, Liverant GI, Brown TA. Psychometric evaluation of the behavioral inhibition/behavioral activation scales in a large sample of outpatients with anxiety and mood disorders. Psychol Assess 2004;16(3):244-254. [doi: 10.1037/1040-3590.16.3.244]

27. Brown TA. Temporal course and structural relationships among dimensions of temperament and DSM-IV anxiety and mood disorder constructs. J Abnorm Psychol 2007 May;116(2):313-328. [doi: 10.1037/0021-843X.116.2.313] [Medline: 17516764]

28. Campbell-Sills L, Barlow DH, Brown TA, Hofmann SG. Effects of suppression and acceptance on emotional responses of individuals with anxiety and mood disorders. Behav Res Ther 2006 Sep;44(9):1251-1263. [doi: 10.1016/j.brat.2005.10.001]

29. Kotov R, Gamez W, Schmidt F, Watson D. Linking 'big' personality traits to anxiety, depressive, and substance use disorders: a meta-analysis. Psychol Bull 2010;136(5):768-821. [doi: 10.1037/a0020327]

30. Lopez S, Snyder C. The Oxford Handbook of Positive Psychology. New York: Oxford University Press; 2009.

31. Gilbert KE, Nolen-Hoeksema S, Gruber J. Positive emotion dysregulation across mood disorders: how amplifying versus dampening predicts emotional reactivity and illness course. Behav Res Ther 2013 Nov;51(11):736-741. [doi: 10.1016/j.brat.2013.08.004] [Medline: 24076407]

32. Sauer-Zavala S, Gutner CA, Farchione TJ, Boettcher HT, Bullis JR, Barlow DH. Current Definitions of "Transdiagnostic" in Treatment Development: A Search for Consensus. Behav Ther 2017 Jan;48(1):128-138. [doi: 10.1016/j.beth.2016.09.004] [Medline: 28077216]

33. Fredrickson BL. The broaden-and-build theory of positive emotions. Philos Trans R Soc Lond B Biol Sci 2004 Sep 29;359(1449):1367-1378 [FREE Full text] [doi: 10.1098/rstb.2004.1512] [Medline: 15347528]

34. Dockray S, Steptoe A. Positive affect and psychobiological processes. Neurosci Biobehav Rev 2010 Sep;35(1):69-75 [FREE Full text] [doi: 10.1016/j.neubiorev.2010.01.006] [Medline: 20097225]

35. Tugade MM, Fredrickson BL. Resilient individuals use positive emotions to bounce back from negative emotional experiences. J Pers Soc Psychol 2004 Feb;86(2):320-333 [FREE Full text] [doi: 10.1037/0022-3514.86.2.320] [Medline: 14769087]

36. Sewart AR, Zbozinek TD, Hammen C, Zinbarg RE, Mineka S, Craske MG. Positive Affect as a Buffer between Chronic Stress and Symptom Severity of Emotional Disorders. Clin Psychol Sci 2019 Sep;7(5):914-927 [FREE Full text] [doi: 10.1177/2167702619834576] [Medline: 31632843]

37. Pressman SD, Jenkins BN, Moskowitz JT. Positive Affect and Health: What Do We Know and Where Next Should We Go? Annu Rev Psychol 2019 Jan 04;70:627-650. [doi: 10.1146/annurev-psych-010418-102955] [Medline: $\underline{30260746]}$

38. Blanco-Donoso LM, Moreno-Jiménez B, Rodríguez-Carvajal R, Garrosa E. Regulación emocional y afecto positivo: el efecto mediador del sentido de la coherencia. Rev Argen Clin Psic 2018;27(3):403-412. [doi: 10.24205/03276716.2018.1079]

39. Bolier L, Haverman M, Westerhof GJ, Riper H, Smit F, Bohlmeijer E. Positive psychology interventions: a meta-analysis of randomized controlled studies. BMC Public Health 2013 Feb 08;13:119 [FREE Full text] [doi: 10.1186/1471-2458-13-119] [Medline: 23390882]

40. Roepke AM, Seligman MEP. Depression and prospection. Br J Clin Psychol 2015 Jun 12;55(1):23-48. [doi: 10.1111/bjc.12087]

41. Titov N, Dear BF, Schwencke G, Andrews G, Johnston L, Craske MG, et al. Transdiagnostic internet treatment for anxiety and depression: a randomised controlled trial. Behav Res Ther 2011 Aug;49(8):441-452. [doi: 10.1016/j.brat.2011.03.007] [Medline: 21679925] 
42. Carl JR, Soskin DP, Kerns C, Barlow DH. Positive emotion regulation in emotional disorders: A theoretical review. Clinical Psychology Review 2013 Apr;33(3):343-360. [doi: 10.1016/j.cpr.2013.01.003]

43. Craske MG, Meuret AE, Ritz T, Treanor M, Dour H, Rosenfield D. Positive affect treatment for depression and anxiety: A randomized clinical trial for a core feature of anhedonia. J Consult Clin Psychol 2019 May;87(5):457-471. [doi: 10.1037/ccp0000396] [Medline: $\underline{\text { 30998048] }}$

44. Kazdin AE. Technology-Based Interventions and Reducing the Burdens of Mental Illness: Perspectives and Comments on the Special Series. Cognitive and Behavioral Practice 2015 Aug;22(3):359-366. [doi: 10.1016/j.cbpra.2015.04.004]

45. Andersson G. Internet-Delivered Psychological Treatments. Annu Rev Clin Psychol 2016;12:157-179. [doi: 10.1146/annurev-clinpsy-021815-093006] [Medline: 26652054]

46. Andersson G, Cuijpers P. Internet-based and other computerized psychological treatments for adult depression: a meta-analysis. Cogn Behav Ther 2009 Dec;38(4):196-205. [doi: 10.1080/16506070903318960] [Medline: 20183695]

47. Andrews G, Basu A, Cuijpers P, Craske M, McEvoy P, English C, et al. Computer therapy for the anxiety and depression disorders is effective, acceptable and practical health care: An updated meta-analysis. J Anxiety Disord 2018 Apr;55:70-78. [doi: 10.1016/j.janxdis.2018.01.001]

48. Cuijpers P, van SA, Warmerdam L, Andersson G. Psychotherapy versus the combination of psychotherapy and pharmacotherapy in the treatment of depression: a meta-analysis. Depress Anxiety 2009;26(3):279-288. [doi: 10.1002/da.20519] [Medline: 19031487]

49. American Psychological Association APA. Diagnostic And Statistical Manual Of Mental Disorders. 4th ed. Washington DC: American Psychiatric Association; 2000:A.

50. Ito M, Horikoshi M, Kato N, Oe Y, Fujisato H, Nakajima S, et al. Transdiagnostic and Transcultural: Pilot Study of Unified Protocol for Depressive and Anxiety Disorders in Japan. Behav Ther 2016 May;47(3):416-430. [doi: 10.1016/j.beth.2016.02.005] [Medline: 27157034]

51. Osma J, Castellano C, Crespo E, Garcia-Palacios A. The unified protocol for transdiagnostic treatment of emotional disorders in group format in a Spanish public mental health setting. Behav Psychol/Psicol Conductual 2015;23(3):447-466. [doi: 10.1093/med-psych/9780190255541.003.0001]

52. Reinholt N, Aharoni R, Winding C, Rosenberg N, Rosenbaum B, Arnfred S. Transdiagnostic group CBT for anxiety disorders: the unified protocol in mental health services. Cogn Behav Ther 2017 Jan;46(1):29-43. [doi: 10.1080/16506073.2016.1227360] [Medline: 27705086]

53. Taylor CT, Lyubomirsky S, Stein MB. Upregulating the positive affect system in anxiety and depression: Outcomes of a positive activity intervention. Depress Anxiety 2017 Mar;34(3):267-280 [FREE Full text] [doi: 10.1002/da.22593] [Medline: 28060463]

54. Moher D, Hopewell S, Schulz K, Montori V, Gøtzsche PC, Devereaux PJ, CONSORT. CONSORT 2010 explanation and elaboration: updated guidelines for reporting parallel group randomised trials. Int J Surg 2012;10(1):28-55 [FREE Full text] [doi: 10.1016/j.ijsu.2011.10.001] [Medline: 22036893]

55. Eysenbach G, CONSORT-EHEALTH Group. CONSORT-EHEALTH: improving and standardizing evaluation reports of Web-based and mobile health interventions. J Med Internet Res 2011 Dec 31;13(4):e126 [FREE Full text] [doi: 10.2196/jmir.1923] [Medline: 22209829]

56. Chan A, Tetzlaff JM, Altman DG, Laupacis A, Gøtzsche PC, Krleža-Jerić K, et al. SPIRIT 2013 statement: defining standard protocol items for clinical trials. Ann Intern Med 2013 Feb 05;158(3):200-207 [FREE Full text] [doi: 10.7326/0003-4819-158-3-201302050-00583] [Medline: 23295957]

57. Chan A, Tetzlaff JM, Gotzsche PC, Altman DG, Mann H, Berlin JA, et al. SPIRIT 2013 explanation and elaboration: guidance for protocols of clinical trials. Br Med J 2013 Jan 09;346(jan08 15):e7586-e7586. [doi: 10.1136/bmj.e7586]

58. Díaz-García A, González-Robles A, Fernández-Álvarez J, García-Palacios A, Baños RM, Botella C. Efficacy of a Transdiagnostic internet-based treatment for emotional disorders with a specific component to address positive affect: Study protocol for a randomized controlled trial. BMC Psychiatry 2017 Apr 20;17(1):-. [doi: 10.1186/s12888-017-1297-z]

59. Faul F, Erdfelder E, Lang A, Buchner A. G*Power 3: A flexible statistical power analysis program for the social, behavioral, and biomedical sciences. Behav Res Methods 2007 May;39(2):175-191. [doi: 10.3758/BF03193146]

60. Ferrando L, Bobes J, Gibert J, Lecubrier Y. Mini international neuropsychiatric interview. In: Manejo De Los Trastornos Mentales Y Del Comportamiento en Atención Primaria. Oviedo: Gofer; 1997.

61. Linehan M. Cognitive-Behavioral Treatment Of Borderline Personality Disorder. New York: The Guilford Press; 2010.

62. Labpsitec. 2011. Psicología y Tecnología https://www.psicologiaytecnologia.com/. URL: https://www. psicologiaytecnologia.com/ [accessed 2015-09-10]

63. Sin NL, Lyubomirsky S. Enhancing well-being and alleviating depressive symptoms with positive psychology interventions: a practice-friendly meta-analysis. J Clin Psychol 2009 May;65(5):467-487. [doi: 10.1002/jclp.20593] [Medline: 19301241]

64. Lejuez CW, Hopko DR, Hopko SD. A brief behavioral activation treatment for depression. Treatment manual. Behav Modif 2001 Apr;25(2):255-286. [doi: 10.1177/0145445501252005] [Medline: 11317637]

65. Seligman ME, Csikszentmihalyi M. Positive psychology: an introduction. Am Psychol 2000;55(1):5-14. [doi: 10.1037/0003-066X.55.1.5] 
66. Fava GA. Well-Being Therapy: conceptual and technical issues. Psychother Psychosom 1999;68(4):171-179. [doi: 10.1159/000012329]

67. Fava GA, Ruini C. Development and characteristics of a well-being enhancing psychotherapeutic strategy: well-being therapy. J Behav Ther Exp Psychiatry 2003 Mar;34(1):45-63. [doi: 10.1016/s0005-7916(03)00019-3]

68. Fredrickson BL. The role of positive emotions in positive psychology: the broaden-and-build theory of positive emotions. Am Psychol 2001;56(3):218-226. [doi: 10.1037/0003-066x.56.3.218]

69. Ekman P, Davidson RJ, Friesen WV. The Duchenne smile: emotional expression and brain physiology. II. J Pers Soc Psychol 1990 Feb;58(2):342-353. [Medline: 2319446]

70. Soussignan R. Duchenne smile, emotional experience, and autonomic reactivity: a test of the facial feedback hypothesis. Emotion 2002 Mar;2(1):52-74. [doi: 10.1037/1528-3542.2.1.52] [Medline: 12899366]

71. Miles L, Johnston L. Detecting Happiness: Perceiver Sensitivity to Enjoyment and Non-Enjoyment Smiles. J Nonverbal Behav 2007 Sep 25;31(4):259-275. [doi: 10.1007/s10919-007-0036-4]

72. Bryant FB. Savoring: a New Model of Positive Experience. Mahwah, NJ: Erlbaum; 2007.

73. Peterson C. Character Strengths and Virtues: a Handbook and Classification. Oxford, UK: Oxford University Press; 2004.

74. Ryff CD, Keyes CL. The structure of psychological well-being revisited. J Pers Soc Psychol 1995 Oct;69(4):719-727. [doi: 10.1037//0022-3514.69.4.719] [Medline: 7473027]

75. Ryff CD. Psychological well-being revisited: advances in the science and practice of eudaimonia. Psychother Psychosom 2014;83(1):10-28 [FREE Full text] [doi: 10.1159/000353263] [Medline: 24281296]

76. Seligman ME, Steen TA, Park N, Peterson C. Positive psychology progress: empirical validation of interventions. Am Psychol 2005;60(5):410-421. [doi: 10.1037/0003-066X.60.5.410] [Medline: 16045394]

77. Sheldon KM, Lyubomirsky S. How to increase and sustain positive emotion: the effects of expressing gratitude and visualizing best possible selves. J Positive Psychol 2006 Apr;1(2):73-82. [doi: 10.1080/17439760500510676]

78. Commify IS. 2019. Trendoo https://www.trendoo.es/. URL: https://www.trendoo.es/ [accessed 2015-09-15]

79. Chakraborty H. A mixed model approach for intent-to-treat analysis in longitudinal clinical trials with missing values. RTI Press Methods Report Series 2009:e. [doi: 10.3768/rtipress.2009.mr.0009.0903] [Medline: 30896910]

80. Hesser H. Modeling individual differences in randomized experiments using growth models: Recommendations for design, statistical analysis and reporting of results of internet interventions. Internet Interv 2015 May;2(2):110-120. [doi: 10.1016/j.invent.2015.02.003]

81. Salim A, Mackinnon A, Christensen H, Griffiths K. Comparison of data analysis strategies for intent-to-treat analysis in pre-test-post-test designs with substantial dropout rates. Psychiatry Res 2008 Sep;160(3):335-345. [doi: 10.1016/j.psychres.2007.08.005]

82. Cohen J. Statistical power analysis for the behavioral sciences. 2nd ed. Hillsdale: N.J: L. Erlbaum Associates; 1988.

83. Jacobson NS, Truax P. Clinical significance: a statistical approach to defining meaningful change in psychotherapy research. J Consult Clin Psychol 1991;59(1):12-19. [doi: 10.1037/0022-006X.59.1.12]

84. Twisk J, de BM, de VW, Heymans M. Multiple imputation of missing values was not necessary before performing a longitudinal mixed-model analysis. J Clin Epidemiol 2013 Sep;66(9):1022-1028. [doi: 10.1016/j.jclinepi.2013.03.017] [Medline: 23790725]

85. Peters SA, Bots ML, den RH, Palmer MK, Grobbee DE, Crouse JR, et al. Multiple imputation of missing repeated outcome measurements did not add to linear mixed-effects models. J Clin Epidemiol 2012 Jun;65(6):686-695. [doi:

10.1016/j.jclinepi.2011.11.012] [Medline: 22459429]

86. Barlow DH, Sauer-Zavala S, Carl JR, Bullis JR, Ellard KK. The nature, diagnosis, and treatment of neuroticism. Clin Psychol Sci 2013 Oct 14;2(3):344-365. [doi: 10.1177/2167702613505532]

87. Wilner Tirpak J, Cassiello-Robbins C, Ametaj A, Olesnycky OS, Sauer-Zavala S, Farchione TJ, et al. Changes in positive affect in cognitive-behavioral treatment of anxiety disorders. Gen Hosp Psychiatry 2019 Nov;61:111-115. [doi: 10.1016/j.genhosppsych.2019.06.008]

88. Meyerhoff J, Rohan KJ. Treatment expectations for cognitive-behavioral therapy and light therapy for seasonal affective disorder: Change across treatment and relation to outcome. J Consult Clin Psychol 2016 Oct;84(10):898-906. [doi: $10.1037 / \mathrm{ccp} 0000121]$

89. Hatchett GT, Park HL. Comparison of four operational definitions of premature termination. Psychother Theo Res Pract Train 2003;40(3):226-231. [doi: 10.1037/0033-3204.40.3.226]

90. Donkin L, Glozier N. Motivators and motivations to persist with online psychological interventions: a qualitative study of treatment completers. J Med Internet Res 2012 Jun;14(3):e91 [FREE Full text] [doi: 10.2196/jmir.2100] [Medline: 22743581]

91. Christensen H, Griffiths KM, Farrer L. Adherence in internet interventions for anxiety and depression. J Med Internet Res 2009 Apr;11(2):e13 [FREE Full text] [doi: 10.2196/jmir.1194] [Medline: 19403466]

92. Erickson DH. Group cognitive behavioural therapy for heterogeneous anxiety disorders. Cogn Behav Ther 2003 Nov;32(4):179-186. [doi: 10.1080/16506070310001686]

93. García-Escalera J, Chorot P, Sandín B, Ehrenreich-May J, Prieto A, Valiente RM. An open trial applying the unified protocol for transdiagnostic treatment of emotional disorders in adolescents (UP-A) adapted as a school-based prevention program. Child Youth Care Forum 2018 Sep 12;48(1):29-53. [doi: 10.1007/s10566-018-9471-0] 
94. Richards D, Richardson T. Computer-based psychological treatments for depression: a systematic review and meta-analysis. Clin Psychol Rev 2012 Jun;32(4):329-342. [doi: 10.1016/j.cpr.2012.02.004] [Medline: 22466510]

95. Baumeister H, Reichler L, Munzinger M, Lin J. The impact of guidance on Internet-based mental health interventions a systematic review. Internet Interv 2014 Oct;1(4):205-215. [doi: 10.1016/j.invent.2014.08.003]

96. Mira A, Bretón-López J, García-Palacios A, Quero S, Baños RM, Botella C. An Internet-based program for depressive symptoms using human and automated support: a randomized controlled trial. Neuropsychiatr Dis Treat 2017 Mar; Volume 13:987-1006. [doi: 10.2147/ndt.s130994]

97. Fernández-Álvarez J, Díaz-García A, González-Robles A, Baños R, García-Palacios A, Botella C. Dropping out of a transdiagnostic online intervention: a qualitative analysis of client's experiences. Internet Interv 2017 Dec;10:29-38. [doi: 10.1016/j.invent.2017.09.001]

98. Carl JR, Gallagher MW, Barlow DH. Development and preliminary evaluation of a positive emotion regulation augmentation module for anxiety and depression. Behav Ther 2018 Nov;49(6):939-950. [doi: 10.1016/j.beth.2017.11.008]

99. Algoe SB, Fredrickson BL. Emotional fitness and the movement of affective science from lab to field. Am Psychol 2011;66(1):35-42. [doi: $10.1037 / \mathrm{a} 0021720$ ]

100. Catalino LI, Fredrickson BL. A Tuesday in the life of a flourisher: the role of positive emotional reactivity in optimal mental health. Emotion 2011;11(4):938-950. [doi: 10.1037/a0024889]

101. Carl JR, Fairholme CP, Gallagher MW, Thompson-Hollands J, Barlow DH. The effects of anxiety and depressive symptoms on daily positive emotion regulation. J Psychopathol Behav Assess 2013 Sep 24;36(2):224-236. [doi: 10.1007/s10862-013-9387-9]

102. Barlow DH, Farchione TJ, Bullis JR, Gallagher MW, Murray-Latin H, Sauer-Zavala S, et al. The unified protocol for transdiagnostic treatment of emotional disorders compared with diagnosis-specific protocols for anxiety disorders: a randomized clinical trial. JAMA Psychiatry 2017 Aug 02:-. [doi: 10.1001/jamapsychiatry.2017.2164] [Medline: 28768327]

103. Mansell W, Harvey A, Watkins E, Shafran R. Conceptual foundations of the transdiagnostic approach to CBT. J Cogn Psychother 2009 Feb 01;23(1):6-19. [doi: 10.1891/0889-8391.23.1.6]

104. Mahoney AE, McEvoy PM. A transdiagnostic examination of intolerance of uncertainty across anxiety and depressive disorders. Cogn Behav Ther 2012 Sep;41(3):212-222. [doi: 10.1080/16506073.2011.622130]

105. Ehring T, Watkins ER. Repetitive negative thinking as a transdiagnostic process. Int J Cogn Ther) 2008 Sep;1(3):192-205. [doi: 10.1521/ijct.2008.1.3.192]

106. Egan SJ, Wade TD, Shafran R. Perfectionism as a transdiagnostic process: a clinical review. Clin Psychol Rev 2011 Mar;31(2):203-212. [doi: 10.1016/j.cpr.2010.04.009] [Medline: 20488598]

107. Aldao A, Nolen-Hoeksema S. Specificity of cognitive emotion regulation strategies: a transdiagnostic examination. Behav Res Ther 2010 Oct;48(10):974-983. [doi: 10.1016/j.brat.2010.06.002]

108. Harvey A, Watkins E, Mansell W, Shafran R. Cognitive behavioural processes across psychological disorders: A transdiagnostic approach to research and treatment. New York: NY: Oxford University Press; 2004:A.

109. Taylor SE, Brown JD. Illusion and well-being: a social psychological perspective on mental health. Psychol Bull 1988;103(2):193-210. [doi: 10.1037/0033-2909.103.2.193]

110. Taylor SE, Kemeny ME, Reed GM, Bower JE, Gruenewald TL. Psychological resources, positive illusions, and health. Am Psychol 2000;55(1):99-109. [doi: 10.1037/0003-066x.55.1.99]

111. Kashdan TB, Rottenberg J. Psychological flexibility as a fundamental aspect of health. Clin Psychol Rev 2010 Nov;30(7):865-878 [FREE Full text] [doi: 10.1016/j.cpr.2010.03.001] [Medline: 21151705]

112. Gloster AT, Meyer AH, Lieb R. Psychological flexibility as a malleable public health target: evidence from a representative sample. J Contextual Behav Sci 2017 Apr;6(2):166-171. [doi: 10.1016/j.jcbs.2017.02.003]

113. Baumeister RF, Vohs KD, Oettingen G. Pragmatic prospection: how and why people think about the future. Rev Gen Psychol 2016 Mar;20(1):3-16. [doi: 10.1037/gpr0000060]

114. Botella C, Molinari G, Fernández-Álvarez J, Guillén V, García-Palacios A, Baños RM, et al. Development and validation of the openness to the future scale: a prospective protective factor. Health Qual Life Outcomes 2018 Apr 23;16(1):-. [doi: 10.1186/s12955-018-0889-8]

\section{Abbreviations}

AG: agoraphobia

BA: behavioral activation

BAI: Beck Anxiety Inventory

BDI-II: Beck Depression Inventory, Second Edition

BI: behavioral inhibition

CBT: cognitive behavioral therapy

CONSORT: Consolidated Standards of Reporting Trials

DD: dysthymic disorder

DSM-IV: Diagnostic and Statistical Manual of Mental Disorders, Fourth Edition 
E: extraversion

EBT: evidence-based psychological treatment

ED: emotional disorder

GAD: generalized anxiety disorder

ICT: information and communication technology

ITT: intention-to-treat

MDD: major depressive disorder

MNAR: missing not at random

$\mathbf{N}$ : neuroticism

NA: negative affect or negative affectivity

NEO FFI: NEO Five Factor Inventory

PA: positive affect

PANAS: Positive and Negative Affect Schedule

PD: panic disorder

RCI: reliable change index

RCT: randomized controlled trial

SAD: social anxiety disorder

TIBP: transdiagnostic internet-based protocol

UP: Unified Protocol

WL: waiting list

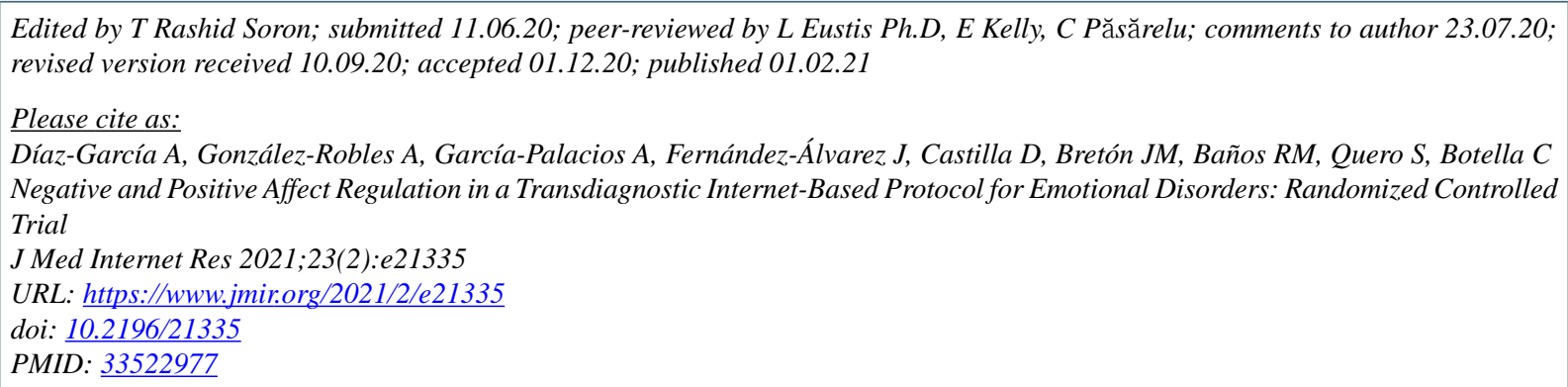

(C)Amanda Díaz-García, Alberto González-Robles, Azucena García-Palacios, Javier Fernández-Álvarez, Diana Castilla, Juana María Bretón, Rosa María Baños, Soledad Quero, Cristina Botella. Originally published in the Journal of Medical Internet Research (http://www.jmir.org), 01.02.2021. This is an open-access article distributed under the terms of the Creative Commons Attribution License (https://creativecommons.org/licenses/by/4.0/), which permits unrestricted use, distribution, and reproduction in any medium, provided the original work, first published in the Journal of Medical Internet Research, is properly cited. The complete bibliographic information, a link to the original publication on http://www.jmir.org/, as well as this copyright and license information must be included. 